NBER WORKING PAPER SERIES

\title{
WORLD FOOD PRICES AND MONETARY POLICY
}

\author{
Luis Catão \\ Roberto Chang \\ Working Paper 16563 \\ http://www.nber.org/papers/w16563
NATIONAL BUREAU OF ECONOMIC RESEARCH
1050 Massachusetts Avenue
Cambridge, MA 02138 \\ December 2010
}

We thank Pietro Cova, Gian Maria Millesi-Ferretti, Bianca de Paoli, Alan Sutherland, Carlos Vegh as well as seminar participants at the Bank of Italy, IADB, IMF, PUC-RJ, the 2009 meeting of the European Econometric Society, and the 2010 World Econometric Society Congress for discussions and comments on an earlier draft. We are also grateful to Marola Castillo for excellent research assistance, to Roberto Rigobon for sharing his food expenditure database with us, and last but not least, to the Research Department of the IADB, where much of this paper was written. The opinions expressed here are, however, the authors' alone and do not necessarily reflect those of any of the above institutions. The views expressed herein are those of the authors and do not necessarily reflect the views of the National Bureau of Economic Research.

NBER working papers are circulated for discussion and comment purposes. They have not been peerreviewed or been subject to the review by the NBER Board of Directors that accompanies official NBER publications.

(C) 2010 by Luis Catão and Roberto Chang. All rights reserved. Short sections of text, not to exceed two paragraphs, may be quoted without explicit permission provided that full credit, including (C notice, is given to the source. 
World Food Prices and Monetary Policy

Luis Catão and Roberto Chang

NBER Working Paper No. 16563

December 2010

JEL No. E5,E6,F41

\begin{abstract}
$\underline{\text { ABSTRACT }}$
In recent years, large fluctuations in world food prices have renewed interest in the question of how monetary policy in small open economies should react to imported price shocks. We address this issue in an open economy setting similar to previous ones except that food plays a distinctive role in utility. A key novelty of our model is that the real exchange rate and the terms of trade can move in opposite directions in response to food price shocks. This has several consequences for observables and for policy. Under a variety of model calibrations, broad CPI targeting emerges as welfare-superior to alternative policy rules once the variance of food price shocks is as large as in real world data.
\end{abstract}

Luis Catão

International Monetary Fund

70019 th Street

Washington DC 20431

and Inter-American Development Bank

LCatao@imf.org

Roberto Chang

Rutgers University

Department of Economics

75 Hamilton Street

New Brunswick, NJ 08901

and NBER

chang@econ.rutgers.edu 


\section{Introduction}

Dramatic swings in world commodity prices in recent years have renewed interest in the issue of how monetary policy in small open economies should react to imported price shocks. Wide fluctuations in food prices have been of particular concern. Given the large weight of food on households' consumption baskets and its limited substitutability with other goods, food price fluctuations can have a sizeable impact on overall consumer prices as well as on terms of trade.

While much has been written on the inflationary effects of oil price shocks and their role in monetary policy (Bodenstein, Erceg and Guerrieri 2008, Kilian 2009, and others), the evidence suggests that food price shocks have been no less important as drivers of global inflation. To illustrate, Figure 1 displays relative food prices against the world price level (proxied by the US WPI) since $1960 .{ }^{1}$ The correlation coefficient is sizeable (0.54). Also, fluctuations in the global relative price of food lead fluctuations in the WPI. More formally, Tables 1 and 2 present correlations and Granger causality tests to allow for a comparison with the inflationary effects of oil price shocks. Restricting attention to the past two decades as in Bodenstein et al. (2008), which coincides with the gradual worldwide adoption of inflation targeting regimes, Table 1 shows that food price cycles bear a closer correlation (either contemporaneous or lagged) than oil price cycles with most indicators of global inflation. Over the entire 1960-2008 period, Granger causality tests in Table 2 reject the hypothesis that food prices do not Granger-cause global inflation, whereas the same hypothesis is not rejected for oil prices. Further, the attendant F-tests suggest that, if anything, food prices Granger-cause oil prices but not the other way around. In short, food prices have been at the centre of major inflexions in global inflation rates.

The large swings in world food prices have translated into significant variations of inflation rates in small open economies. This includes not only earlier episodes when those economies often operated looser monetary regimes, but also the latest boom and bust which took place under the discipline of inflation targeting (IT). As shown by the cross-country medians depicted in Figure 2, large deviations from central targets for consumer price inflation (CPI) were observed, with inflation rates breaching the upper IT tolerance bands in some cases ${ }^{2}$. Only

\footnotetext{
${ }^{1}$ More precisely, the figure displays HP-filter detrended fluctuations in the IMF index of US\$ price of non-fuel commodities relative to the overall US wholesale price index (WPI), and the year-on-year fluctuations in the absolute global WPI.

${ }^{2}$ The Chilean experience provides a vivid illustration. The 12-month CPI inflation rose from
} 
when world food prices underwent a steep decline, following the global financial crisis in September 2008, did national inflation rates recede and the attendant deviations from central inflation targets narrow sharply.

Insofar as world food price shocks are exogenous to small open economies, these developments pose an important question for their central bankers: Should they tolerate big fluctuations in CPI inflation if driven by food prices, and thus accommodate at least partially the external relative price shocks, as long as producer price inflation (PPI) remains within target? ${ }^{3}$ Or should they instead react forcefully to CPI inflation, possibly requiring much lower inflation (or even deflation) rates in non-commodity domestic sectors? To elucidate the answer, this paper investigates the transmission mechanisms from imported commodity price shocks to output and inflation in a small open economy model, and measures the welfare implications of different monetary policy rules. In particular, the paper examines which of the targeting rules typically employed by central banks, broad CPI targeting, producer price index (PPI) targeting, or exchange rate targeting, delivers the highest welfare if the small open economy faces sizeable external fluctuations in the price of a key item in the domestic consumption basket such as food.

The context for our analysis is that of a small open economy which is a net food importer and where food represents a sizeable share of household spending. Our model builds on the now canonical model of Gali and Monacelli (2005), which is itself a variant of a wider class of recent New Keynesian models (Woodford 2003, Walsh, 2004, and Gali 2008). But we impose several departures, including: i) allowing global food prices to vary widely relative to the overall world price index; ii) letting food expenditure shares to differ between the small open economy and the rest of the world; iii) taking the peculiar nature of food commodities into account by separating out its role in utility from that of domestic goods. That (i) is warranted is clear from Figure 1. Table 3 provides cross-country evidence for (ii): emerging economies tend to allocate a larger share of consumption expenditure

around $3 \%$ in 2005 to as high as $9.3 \%$ by 2008Q3, well away from the official IT range for broad CPI (2-4\% a year). As commodity prices collapsed since, inflation has receeded to low single digit levels, back to within the IT tolerance bands by late 2009 .

${ }^{3}$ An affirmative answer appears to have characterized the latest cycle. Estimated Taylor rule coefficients on CPI inflation for all IT countries show sizeable and statistically significant drops during the 2007q1-2008q3 food price upswing. This suggests leniency on the part of national central banks in responding to the imported food inflation as prescribed by broad CPI targeting. The respective country regressions are not reported here to save on space but are available from the authors upon request. 
into food than more advanced peers, and in some cases substantially so. Regarding (iii), there is ample evidence on other peculiar characteristics of food commodities, besides its high weight on spending, which has been glossed over in previous open economy models and yet clearly justifies separating it out from other goods composite. ${ }^{4}$

Correspondingly, our model has novel implications for key variables. Most notably, in response to relative external price shocks (in our case food prices), the terms of trade (TOT) and the real exchange rate (RER) can move in opposite directions. Because we assume that food has a higher weight in the domestic consumption basket than in the foreign one, higher world food prices can increase the cost of consumption at home relative to that abroad (a RER appreciation) while weakening the relative price of domestic output (a fall in the terms of trade). In contrast, Cova and Sondegaard 2004, Gali and Monacelli, 2005, de Paoli, 2009, and many others assume that food price shocks are absent, which implies that TOT and the RER always move in the same direction.

The implication that RER and TOT do not always move in the same direction not only adds realism to our model but also allows for more varied comovements between observables. In previous models, for instance, shocks that cause a TOT deterioration must also result in a RER depreciation, and hence higher output (because domestic output has become relatively cheaper) and higher consumption (because of complete international risk sharing). But our model implies, as we have mentioned, that RER and TOT do not always move in the same direction, and hence allows for more complex patterns of comovements between output and consumption. .

Likewise, implications for policy and welfare can be quite different from those of previous models. In those, for example, the small open economy under study becomes isomorphic to a closed one if preferences are Cobb-Douglas and the price elasticity of exports is one. The consequence is that the main friction to be addressed by monetary policy is domestic price stickiness, so domestic PPI targeting

\footnotetext{
${ }^{4}$ One is that food has low price elasticities of substitution with other goods. This, together with the average high share in spending, implies that food price shocks should have a nontrivial impact on marginal rates of substitution and labor supply. In addition, food is a highly competitive industry, displaying fast pass-through from cost shocks to prices, as well as high price volatility (Gouveia 2007). This makes food very different from the typical composite good variety in models featuring staggered sectoral prices. Finally, many IT countries are large net food importers or exporters. In these cases, swings in the relative world price of food can entail large terms of trade variations.
} 
emerges as a welfare maximizing rule. In our model, however, the small open economy does not become isomorphic to a closed one even under the unit elasticity assumptions just mentioned (in such a case, output does equal natural output at all times and trade is balanced, but the RER, and therefore consumption, moves with world relative price shocks).

More generally, a variety of model calibrations confirm and complement our theoretical discussion. We discuss how the presence of world relative shocks influence the impulse responses of main macro aggregates. Also, we show that the welfare rankings of alternative policies can be overturned, relative to previous studies, when world relative price shocks are realistically large. More specifically, when the variance of food price shocks is calibrated to be as large as in real world data, CPI targeting and fixed exchange rates tend to lower the volatility of the RER, have more expansionary effects on output, and appreciate the mean RER. This, in turn, allows the country to better take advantage of the so-called terms of trade externality (that is, to consume more per unit of domestic output and thus, given disutility of labor effort, enhance welfare). However, the volatility of output and employment, and domestic inflation, is higher relative to a PPI targeting rule. So significant policy trade-offs are at stake. These trade-offs relate to how the distinct policies exploit relative price covariances, notably that between the TOT and RER. While the role of the terms of trade externality in weakening the welfare dominance of PPI targeting has been noted before for particular parametrizations of the canonical model (Cova and Sondegaard, 2004, de Paoli, 2009), we establish the welfare dominance of CPI targeting under a much broader array of calibrations. We also emphasize how that dominance relates to the relative variance of food price shocks coupled with the weight of food in national consumption baskets. Indeed, we show that when food price shocks are small enough, our model delivers the same policy rankings as the previous literature.

The remainder of the paper is as follows. Section 2 lays out the model. Section 3 discusses Phillips curve relationships, fleshing out how inflation and the appropriate measure of the output gap are affected by changes in world relative food prices. Section 4 discusses the dynamic IS curve and impulse responses. Section 5 examines welfare and the ranking of the monetary policy rules for a wide range of numerical calibrations. Section 6 sums up the results and discusses additional policy implications. 


\section{Model}

We study a small open economy populated by identical agents that consume a domestic good and imported food. The domestic good is an aggregate of intermediate varieties produced at home with domestic labor. The intermediates sector is characterized by monopolistic competition and nominal rigidities, as in recent New Keynesian (NK) models. The composition of the CPI indices at home and abroad differ, so PPP does not necessarily hold. Given nominal rigidities, domestic policy can affect the real exchange rate (RER) and the terms of trade (TOT), and thus manipulate the latter to the country's advantage (the so-called terms of trade externality). Marginal costs depend on openness and international relative prices as in the canonical NK setting, but a main distinction is that relative prices depend on the exogenous world price of food.

\subsection{Households}

The economy under study has a representative agent with preferences:

$$
E \sum_{t=0}^{\infty} \beta^{t} U_{t}
$$

where $0<\beta<1, E($.$) is the expectation operator, and$

$$
U_{t}=\frac{C_{t}^{1-\sigma}}{\varsigma(1-\sigma)}-\int_{0}^{1} \frac{N_{t}(j)^{1+\varphi}}{1+\varphi} d j
$$

$\sigma, \varphi$, and $\varsigma$ are parameters, $C_{t}$ denotes consumption, and $N_{t}(j)$ is the supply of labor employed by a firm belonging to industry $j \in[0,1]$. As in Woodford (2003), we assume that there is a continuum of industries, that each of which employs a different type of labor, and that labor types are not perfect substitutes from the viewpoint of the household.

Consumption is a C.E.S. aggregate of a home final good $C_{h}$ and an imported $\operatorname{good}\left(\right.$ food) $C_{f}$ :

$$
C_{t}=\left[(1-\alpha)^{1 / \eta} C_{h t}^{(\eta-1) / \eta}+\alpha^{1 / \eta} C_{f t}^{(\eta-1) / \eta}\right]^{\eta /(\eta-1)}
$$

where $\eta$ is the elasticity of substitution between home and foreign goods, and $\alpha$ is a measure of the degree of openness. 
The price index associated with $C$, or CPI, expressed in domestic currency, is

$$
P_{t}=\left[(1-\alpha) P_{h t}^{1-\eta}+\alpha P_{f t}^{1-\eta}\right]^{1 /(1-\eta)}
$$

where $P_{h t}$ and $P_{f t}$ are the domestic currency prices of the home good and imports. Also, given total consumption $C_{t}$ and prices $P_{h t}$ and $P_{f t}$, optimal demands for home goods and foreign goods are given by

$$
\begin{gathered}
C_{h t}=(1-\alpha)\left(\frac{P_{h t}}{P_{t}}\right)^{-\eta} C_{t} \\
C_{f t}=\alpha\left(\frac{P_{f t}}{P_{t}}\right)^{-\eta} C_{t}
\end{gathered}
$$

Note that, if $P_{h t}=P_{f t}, \alpha$ equals the fraction of all consumption that is imported. In this sense, $\alpha$ is a measure of openness. Home bias corresponds to the case $\alpha<1 / 2 .{ }^{5}$

The agent chooses consumption and labor effort taking prices and wages as given, and having unfettered access to the world financial market. We assume that the latter is characterized by complete markets. Finally, the agent owns domestic firms and receives their profits.

The resulting maximization problem is well known (see e.g. Gali and Monacelli $2005)$. One implication is that, if $W_{t}(j)$ is the domestic wage for labor of type $j$, optimal labor supply is given by the equality of the marginal disutility of labor with the marginal utility of the real wage:

$$
{ }_{\varsigma} C_{t}^{\sigma} N(j)_{t}^{\varphi}=\frac{W_{t}(j)}{P_{t}}
$$

Also, complete financial markets imply that

$$
C_{t}=\kappa C_{t}^{*} X_{t}^{1 / \sigma}
$$

where $\kappa$ is a positive constant, $C_{t}^{*}$ is an index of world consumption, and $X_{t}$ is the real exchange rate, that is, the ratio of the price of the world consumption index to the domestic CPI, measured in a common currency. ${ }^{6}$

Finally, the domestic safe interest rate is given by

$$
\frac{1}{1+i_{t}}=\beta E_{t}\left[\left(\frac{C_{t+1}}{C_{t}}\right)^{-\sigma} \frac{P_{t}}{P_{t+1}}\right]
$$

\footnotetext{
${ }^{5}$ We have assumed $\eta \neq 1$. If $\eta=1, C_{t}$ and $P_{t}$ are Cobb Douglas.

${ }^{6}$ To be sure, we have employed the assumption that the marginal utility of consumption in the rest of the world is proportional to $C_{t}^{*-\sigma}$.
} 


\subsection{Prices}

For simplicity, we assume that all food is imported, and that the world price of food is exogenously given in terms of a world currency. Using asterisks to denote prices denominated in world currency, the domestic currency price of food is then

$$
P_{f t}=S_{t} P_{f t}^{*}
$$

where $S_{t}$ is the (nominal) exchange rate (domestic currency per unit of foreign currency). So, there is full pass through from world to domestic food prices.

Likewise, we assume that the world currency price of the world consumption index is exogenous. ${ }^{7}$ Denoting it by $P_{t}^{*}$, the real exchange rate is then:

$$
X_{t}=S_{t} P_{t}^{*} / P_{t}
$$

It is useful also to define the domestic price of food relative to the price of home output, or terms of trade, by

$$
Q_{t}=\frac{P_{f t}}{P_{h t}}=\frac{S_{t} P_{f t}^{*}}{P_{h t}}
$$

As in other models, the terms of trade and the relative price of home output are essentially the same, since 1 implies that

$$
\left(\frac{P_{t}}{P_{h t}}\right)^{1-\eta}=(1-\alpha)+\alpha Q_{t}^{1-\eta}
$$

Other models also imply that the real exchange rate and the terms of trade are tightly related. In our model, however, that relation is less tight. To see this, inserting the expressions for $X_{t}$ and $P_{f t}$ into the consumer price index (1) yields

\footnotetext{
${ }^{7}$ In solving the model, and to simplify the algebra, we will in fact assume something stronger: that shocks to $C^{*}$ and $Z^{*}$ are independent from each other. To justify this, one can assume that food has a negligible share in the world consumer basket, in contrast with the domestic basket. This is a defensible assumption since, as shown in Table 3, the food share in the CPI is substantially higher in small emerging economies than in advanced countries.

It is also worth stressing that the presence of food price shocks is consistent with perfect insurance: since 4 holds at all times, the home agent is implicitly purchasing all the insurance he needs given the price of risk.
} 
the following relation between the real exchange rate and the relative price of home final goods:

$$
1=(1-\alpha)\left(\frac{P_{h t}}{P_{t}}\right)^{1-\eta}+\alpha X_{t}^{1-\eta} Z_{t}^{* 1-\eta}
$$

where $Z_{t}^{*}=P_{f t}^{*} / P_{t}^{*}$ is the world's relative price of food, which we take as exogenous.

An improvement in the terms of trade (a fall in $Q_{t}$ ) implies an increase in the relative price of domestic output $\left(P_{h} / P\right)$. Given $Z_{t}^{*}, 7$ then implies that $X_{t}$ must fall (a real appreciation). But $X_{t}$ and $Q_{t}$ can move in opposite directions when $Z_{t}^{*}$ moves.

Since this aspect of our model is largely responsible for the novelty of our results, it deserves further elaboration. Other models have typically assumed that home agents consume a domestic aggregate and a foreign aggregate (such as $C^{*}$ in our model), and that there is some home bias, so that PPP does not hold. In contrast, we assume that home agents do not consume the foreign aggregate but instead a different good (food). This would not make a difference if the relative price of food were fixed in terms of the foreign aggregate (e.g. if $Z^{*}=1$ ). So the basic differences between our model and previous ones emerge because $Z^{*}$ is allowed to fluctuate.

In particular, the standard specification (with $Z^{*}$ constant) implies, as can be seen from the three previous expressions, a very tight link between the terms of trade and the real exchange rate: with $Z^{*}=1, X_{t}$ and $Q_{t}$ must always move in the same direction. In addition, using lowercase variables for logged variables, one can show that $x_{t}=(1-\alpha) q_{t}$ to a first order approximation, so that (to second order) $\operatorname{Var}\left(x_{t}\right)=(1-\alpha)^{2} \operatorname{Var}\left(q_{t}\right)$ : the variance of the real exchange rate is proportional to the variance of the terms of trade, the constant of proportionality being less than one and pinned down by the degree of openness. These implications seem quite restrictive.

In our model, in contrast, fluctuations in the relative price of food mean that $X_{t}$ and $Q_{t}$ can move in opposite directions (in response of shocks to $Z^{*}$ ). Also, in a first order approximation, we will see that $x_{t}=(1-\alpha) q_{t}-z_{t}$, so that the variance of $x$ can be smaller or larger than the variance of $q$, depending on the volatility of $z$. 


\subsection{Domestic Production}

The home final good can be obtained by assembling intermediate goods varieties, indexed by $j \in[0,1]$ :

$$
Y_{h t}=\left[\int_{0}^{1} Y_{t}(j)^{(\varepsilon-1) / \varepsilon} d j\right]^{\varepsilon /(\varepsilon-1)}
$$

where $\varepsilon$ is the elasticity of substitution between domestic varieties. Minimizing the cost of producing the aggregate implies that, given $Y_{h t}$, the demand for each variety is given by

$$
Y_{t}(j)=\left(\frac{P_{t}(j)}{P_{h t}}\right)^{-\varepsilon} Y_{h t}
$$

where $P_{t}(j)$ is the price of variety $j$, and $P_{h t}$ is the relevant price index:

$$
P_{h t}=\left[\int_{0}^{1} P_{t}(j)^{1-\varepsilon} d j\right]^{1 /(1-\varepsilon)}
$$

Variety $j$ of intermediates is produced by only labor of type $j$ according to the production function

$$
Y_{t}(j)=A_{t} N_{t}(j)
$$

where $N_{t}(j)$ is the employment of type $j$ labor and $A_{t}$ is a productivity shock, common to all firms in the economy.

Firms take wages as given. We allow for the existence of a subsidy to employment at constant rate $v$. Hence nominal marginal cost is given by

$$
\Psi_{j t}=(1-v) W_{t}(j) / A_{t}
$$

where $W_{t}(j)$ is the wage rate for type $j$ labor.

Variety producers are monopolistic competitors and set prices in domestic currency as in Calvo (1983): each individual producer is allowed change nominal prices with probability $(1-\theta)$. As is now well known, all producers with the opportunity to reset prices in period $t$ will choose the same price, say $\bar{P}_{t}$, which satisfies:

$$
\sum_{k=0}^{\infty} \theta^{k} E_{t}\left[M_{t, t+k} Y_{t+k \mid t}\left(\bar{P}_{t}-\frac{\varepsilon}{\varepsilon-1} \Psi_{t+k \mid t}\right)\right]=0
$$


where $Y_{t+k \mid t}$ is the demand in period $t+k$ for a producer that last set her price in period $t$ :

$$
Y_{t+k \mid t}=\left(\frac{\bar{P}_{t}}{P_{h t+k}}\right)^{-\varepsilon} Y_{h t+k}
$$

$M_{t, t+j}$ is the period $t$ pricing kernel applicable to nominal payoffs in period $t+j$, and $\Psi_{t+k \mid t}$ is the nominal marginal cost of production at $t+k$ for producers that set their prices at $t$.

It also follows (from 8) that the price of the home final good is given by:

$$
P_{h t}=\left[(1-\theta) \bar{P}_{t}^{1-\varepsilon}+\theta P_{h, t-1}^{1-\varepsilon}\right]^{1 /(1-\varepsilon)}
$$

\subsection{Equilibrium}

We assume that the foreign demand for the domestic aggregate is given by a function of its price relative to $P_{t}^{*}$ and the index $C_{t}^{*}$ of world consumption. Hence market clearing for the home aggregate requires:

$$
Y_{h t}=C_{h t}+\phi\left(\frac{P_{h t}}{S_{t} P_{t}^{*}}\right)^{-\gamma} C_{t}^{*}
$$

where $\phi$ is a constant and $\gamma$ is the price elasticity of the foreign demand for home exports. $^{8}$

Equilibrium is determined once a rule for monetary policy is specified.

\subsection{Output and Relative Prices}

Because of nominal rigidities, domestic output is demand determined. Demand is, in turn, a function of the key relative prices in this model. Understanding the relation between output, demand, and relative prices is crucial for the ensuing analysis.

Combining the preceding expression for the demand for home produce with (2) and the definition of the real exchange rate to get:

$$
\begin{aligned}
Y_{h t} & =(1-\alpha)\left(\frac{P_{h t}}{P_{t}}\right)^{-\eta} C_{t}+\phi X_{t}^{\gamma}\left(\frac{P_{h t}}{P_{t}}\right)^{-\gamma} C_{t}^{*} \\
& =C_{t}^{*}\left[\kappa(1-\alpha)\left(\frac{P_{h t}}{P_{t}}\right)^{-\eta} X_{t}^{1 / \sigma}+\phi X^{\gamma}\left(\frac{P_{h t}}{P_{t}}\right)^{-\gamma}\right]
\end{aligned}
$$

\footnotetext{
${ }^{8}$ Note that, unlike Cova and Sondegaard (2004) and de Paoli (2009), we allow the home and foreign elasticities of demand for home goods, $\gamma$ and $\eta$, to differ.
} 
where we have used 4 for the second equality.

This expression emphasizes that the demand for domestic output depends on three variables. The first one is world consumption, which affects proportionally not only foreign demand for home produce but also domestic demand via the risk sharing condition 4 . The second one is the real exchange rate. Because of risk sharing, an increase in $X_{t}$ (a real depreciation) implies an increase in domestic consumption (with elasticity $1 / \sigma$ ), a fraction $(1-\alpha)$ of which accrues to domestic goods. Also, ceteris paribus, the increase in $X_{t}$ means a fall in the world relative price of home exports, and hence an increase in foreign demand for home goods, with elasticity $\gamma$. The third factor is the domestic relative price of home output $P_{h t} / P_{t}$ or, equivalently, the terms of trade. Holding fixed $X_{t}$ and $C_{t}^{*}$, a terms of trade deterioration (an increase in $Q_{t}$, or a fall in $P_{h} / P$ ) reduces the relative price of home output in terms of both domestic and foreign consumption. This increases the demand for home goods, with elasticities $\eta$ and $\gamma$ respectively.

As we noted previously, in the absence of food price shocks, $X_{t}$ and $Q_{t}$ must move in the same direction. Hence $13 Y_{h t}$ must also move in that direction. In response to food price shocks, however, $X_{t}$ and $Q_{t}$ can move in different directions, so that the impact on $Y_{h t}$ is ambiguous.

\section{Relative Prices and the Open Economy Phillips Curve}

The possibility of imported inflation has a significant effect on the derivation of the aggregate supply relation characterizing the tradeoffs between output and inflation in the economy. To understand this, here we examine a first order log linear approximation of the model around a nonstochastic steady state with zero inflation.

\subsection{Inflation and Marginal Costs}

We shall use lowercase variables to denote logs. Starting with the pricing equations, and following Gali (2008, p.45), one can rewrite 10 as

$$
\sum_{k=0}^{\infty} \theta^{k} E_{t}\left[M_{t, t+k} Y_{t+k \mid t}\left(\frac{\bar{P}_{t}}{P_{h, t-1}}-\frac{\varepsilon}{\varepsilon-1} M C_{t+k \mid t} \Pi_{t-1, t+k}^{h}\right)\right]=0
$$

where

$$
M C_{t+k \mid t}=\Psi_{t+k \mid t} / P_{h, t+k}
$$


denotes marginal cost in terms of domestic goods for those firms that set prices in period $t$. A first order approximation then yields:

$$
\bar{p}_{t}-p_{h, t-1}=(1-\beta \theta) \sum_{k=0}^{\infty}(\beta \theta)^{k} E_{t}\left(m c_{t+k \mid t}-m c\right)+\left(p_{h, t+k}-p_{h, t-1}\right)
$$

where $m c=\log (\varepsilon-1) / \varepsilon=-\mu$ is the steady state value of marginal costs.

To gain insight on the previous expressions, note that

$$
\begin{aligned}
M C_{t+k \mid t} & =\Psi_{t+k \mid t} / P_{h, t+k} \\
& =(1-v) W_{t+k \mid t} / A_{t+k} P_{h, t+k} \\
& =(1-v) \varsigma C_{t+k}^{\sigma} N_{t+k \mid t}^{\varphi} P_{t+k} / A_{t+k} P_{h, t+k}
\end{aligned}
$$

where the last expression follows from 3. Now, our assumptions about production imply that $N_{t+k \mid t}=Y_{t+k \mid t}$ which, together with 11 and the previous expression gives

$$
M C_{t+k \mid t}=M C_{t+k}\left(\frac{\bar{P}_{t}}{P_{h t+k}}\right)^{-\varphi \varepsilon}
$$

where

$$
M C_{t}=\left[(1-v) \varsigma C_{t}^{\sigma} P_{t} / A_{t}^{1+\varphi} P_{h t}\right] Y_{h t}^{\varphi}
$$

is a measure of marginal cost averaged across firms. This says that the marginal cost of production at $t+k$ for a firm that last set its price at $t$ depends on average marginal cost times the term $\left(\frac{\bar{P}_{t}}{P_{h t+k}}\right)^{-\varphi \varepsilon}$, which reflects the difference between the demand for that firm's output and aggregate demand due to that firm's relative price.

Log linearizing the two preceding expressions yield:

$$
m c_{t+k \mid t}=m c_{t+k}+\varphi \varepsilon\left(p_{h t+k}-\bar{p}_{t}\right)
$$

and

$$
m c_{t}=-v+\log \varsigma+\sigma c_{t}+\varphi y_{h t}-(1+\varphi) a_{t}+\left(p_{t}-p_{h t}\right)
$$

To proceed further, use the linearized version of 4 and 1 to get

$$
m c_{t}=-v+\log \varsigma+\sigma \log \kappa+\sigma c_{t}^{*}+\varphi y_{h t}+x_{t}+\alpha q_{t}-(1+\varphi) a_{t}
$$


This emphasizes that average marginal costs depend on the real exchange rate and the terms of trade, in addition to domestic production $y_{h t}$ and exogenous shocks. The $\alpha q_{t}$ term determines the price of home output in terms of home consumption, which matters because of the discrepancy between the product wage and the consumption wage. The real exchange rate $x$ affects marginal costs because of its impact on domestic consumption (via international risk sharing) and, therefore, the disutility of labor.

Of course, the real exchange rate and the terms of trade are both endogenous variables that are determined by equilibrium. The approximate relation between them in our setting is given by

$$
x_{t}=(1-\alpha) q_{t}+\left(p_{t}^{*}-p_{f t}^{*}\right)=(1-\alpha) q_{t}-z_{t}^{*}
$$

where $z_{t}^{*}=p_{f t}^{*}-p_{t}^{*}$ is the $\log$ of the world relative price of imports. As already stressed, if world relative prices were constant, $z_{t}^{*}$ would be zero, and the real exchange rate would be proportional to the terms of trade. But here world relative price changes do matter and have to be taken into account. One consequence is that $x_{t}$ and $q_{t}$ can move in opposite directions, in response to shocks in the relative price of food.

We are ready to obtain a relation between domestic (producer) inflation and marginal costs of the kind emphasized in the NK literature. Replacing 17 in 15 and rearranging we obtain:

$$
\left(\bar{p}_{t}-p_{h t-1}\right)=(1-\beta \theta) \sum_{k=0}^{\infty}(\beta \theta)^{k} E_{t} \frac{1}{1+\varphi \varepsilon}\left(m c_{t+k}-m c\right)+\sum_{k=0}^{\infty}(\beta \theta)^{k} E_{t} \pi_{h t+k}
$$

Combining this expression and the linearized version of 12 leads to:

$$
\pi_{h t}=\beta E_{t} \pi_{h, t+1}+\lambda\left(m c_{t}+\mu\right)
$$

where

$$
\lambda=\frac{(1-\beta \theta)(1-\theta)}{\theta} \frac{1}{1+\varphi \varepsilon}
$$

As mentioned, this says that domestic inflation depends on its own expected future value as well as marginal costs. In contrast with previous papers, however, marginal costs depend not only on domestic production but also on the relative price term $x_{t}+\alpha q_{t}=q_{t}-z_{t}^{*}$, that is, on the terms of trade and the real exchange rate. At least one of these has to be treated as an endogenous variable. 


\subsection{The Phillips Curve}

We can proceed as in the recent work of Woodford (2003) and others to usefully summarize the impact of exogenous shocks with the concept of output gap. Here, another gap turns out to be useful, that of a terms of trade gap.

In an equilibrium with flexible prices, monopolistic competitors would set prices to be a constant markup over marginal costs. This implies that the log of marginal cost would be equal to $-\mu$. In such a natural equilibrium, therefore, domestic output and the terms of trade would have to satisfy the corresponding version of $(18)^{9}$ :

$$
-\mu=-v+\log \varsigma+\sigma \log \kappa+\varphi y_{h t}^{n}+q_{t}^{n}+\sigma c_{t}^{*}-z_{t}^{*}-(1+\varphi) a_{t}
$$

where output and the terms of trade have been given a superscript $n$ to indicate "natural".

Substracting the last equation from (18) then gives:

$$
m c_{t}+\mu=\varphi\left(y_{t}-y_{h t}^{n}\right)+\left(q_{t}-q_{t}^{n}\right)
$$

This says that the deviation of marginal costs from their flexible price value depends on the departures of domestic output and the terms of trade from their natural values. The first term is the one emphasized in the conventional literature, but the second term is not.

One can then insert the last equation into (20) to obtain an equation:

$$
\pi_{h t}=\beta E_{t} \pi_{h, t+1}+\lambda \varphi\left(y_{t}-y_{h t}^{n}\right)+\lambda\left(q_{t}-q_{t}^{n}\right)
$$

which can be seen as a version of the New Keynesian Phillips Curve. This in fact is similar to others found in the literature (e.g. Gali and Monacelli 2005), except that the tradeoff between inflation and domestic production is shifted by the terms of trade gap. In this setup, however, such a deviation is endogenous, with significant implications.

Now, recall that 14 is the key link between the demand for domestic output and relative prices. Log linearizing it gives:

$$
\begin{aligned}
y_{h t} & =c_{t}^{*}+\left\{\omega\left[\eta\left(p_{t}-p_{h t}\right)+\frac{1}{\sigma} x_{t}\right]+(1-\omega) \gamma\left(x_{t}+p_{t}-p_{h t}\right)\right\} \\
& =c_{t}^{*}+\left\{\omega\left[\eta \alpha q_{t}+\frac{1}{\sigma} x_{t}\right]+(1-\omega) \gamma\left(x_{t}+\alpha q_{t}\right)\right\} \\
& =c_{t}^{*}+q_{t}\left[\omega\left(\eta \alpha+\frac{(1-\alpha)}{\sigma}\right)+(1-\omega) \gamma\right]-z_{t}^{*}\left(\frac{\omega}{\sigma}+(1-\omega) \gamma\right)
\end{aligned}
$$

\footnotetext{
${ }^{9}$ We use $\left(x_{t}+\alpha q_{t}\right)=q_{t}-z_{t}^{*}$
} 
where we have used the linearized version of 6 for the second equality and 19 for the third one.

Since this holds under flexible prices, the natural levels of output and terms of trade must satisfy:

$$
y_{h t}^{n}=c_{t}^{*}+q_{t}^{n}\left[\omega\left(\eta \alpha+\frac{(1-\alpha)}{\sigma}\right)+(1-\omega) \gamma\right]-z_{t}^{*}\left(\frac{\omega}{\sigma}+(1-\omega) \gamma\right)
$$

The two preceding expressions then imply:

$$
\Theta\left(y_{t}-y_{h t}^{n}\right)=\left(q_{t}-q_{t}^{n}\right)
$$

where

$$
1 / \Theta=\left[\omega\left(\eta \alpha+\frac{(1-\alpha)}{\sigma}\right)+(1-\omega) \gamma\right]
$$

Inserting in 22 yields a Phillips curve that finally looks like a conventional one:

$$
\pi_{h t}=\beta E_{t} \pi_{h, t+1}+\chi\left(y_{t}-y_{h t}^{n}\right)
$$

where

$$
\chi=\lambda\{\varphi+\Theta\}
$$

While the preceding form of the Phillips curve agrees with conventional ones, the similarity is misleading. First, the slope of the Phillips Curve (given by $\chi$ ) depends on various elasticities and parameters of the model, including the degree of openness $\alpha$. This is because our final Phillips curve summarizes not only the conventional effect of the output gap on marginal costs and domestic inflation, but also the effects of the terms of trade gap on the latter.

Second, and more importantly, the natural rate of output moves around with the shocks in the model, including the world relative price shocks $z_{t}^{*}$. Some straightforward algebra yields the solution for the natural rate of output:

$y_{h t}^{n}=\frac{1}{(\varphi+\Theta)}\left(-\mu-(\sigma-\Theta) c_{t}^{*}+\Theta[\omega \alpha(\eta-1 / \sigma)] z_{t}^{*}+v-\log \varsigma-\sigma \log \kappa+(1+\varphi) a_{t}\right)$

It is straightforward to show that, if $\eta=\gamma=1 / \sigma$,the coefficients on foreign demand $\left(c_{t}^{*}\right)$ and world food prices $\left(z_{t}^{*}\right)$ will be zero. In this case, natural output fluctuates only in response to productivity shocks.

To understand these results, refer to Figure 3. Under flexible prices, the marginal cost equation 21 implies a relationship such as MM between $q_{t}^{n}$ and $y_{t}^{n}$, with 
slope $-\varphi$. In turn, the market clearing condition 23 induces a relationship such as DD, with slope $\Theta$. The natural levels of output and the terms of trade are then given by a point such as $\mathrm{E}$ in the figure. An increase in the relative price of food, say a unit shock to $z_{t}^{*}$, shifts MM up by the same amount (one unit). The same shock shifts DD up by $\Theta\left(\frac{\omega}{\sigma}+(1-\omega) \gamma\right)$. Accordingly, a positive shock to $z_{t}^{*}$ always causes an increase in $q_{t}^{n}$ (a deterioration in the natural terms of trade). And the shock will result in an increase in $y_{t}^{n}$ if and only if $\Theta\left(\frac{\omega}{\sigma}+(1-\omega) \gamma\right)$ is less than unity, as in that case the vertical shift of DD will be smaller that of MM. But the sign of $\left[1-\Theta\left(\frac{\omega}{\sigma}+(1-\omega) \gamma\right)\right]$ is equal to the sign of $\eta-1 / \sigma$.

Why is the relation between $\eta$ and $1 / \sigma$ the key one? Use the definition of the real exchange rate $X_{t}=S_{t} P_{t}^{*} / P_{t}$ to rewrite the market clearing condition 14 as

$$
Y_{h t}=C_{t}^{*}\left[\kappa(1-\alpha)\left(\frac{P_{h t}}{S_{t} P_{t}^{*}}\right)^{-\eta} X_{t}^{\frac{1}{\sigma}-\eta}+\phi\left(\frac{P_{h t}}{S_{t} P_{t}^{*}}\right)^{-\gamma}\right]
$$

This expression expresses the demand for home goods a a function of world consumption, the real exchange rate, and the world relative price of home goods, $P_{h t} / S_{t} P_{t}^{*}$. If world consumption and the world relative price of home goods are fixed, the effect of the real exchange rate on $Y_{h t}$, depends only on $\eta-1 / \sigma$. A one percent increase in $X_{t}$ (a real depreciation) increases domestic consumption by $1 / \sigma$ percent via risk sharing. But, given $P_{h t} / S_{t} P_{t}^{*}$, a one percent increase in $X_{t}$ also implies a one percent increase in the domestic relative price of home output. This leads to substitution away from home goods and causes domestic demand to fall by $\eta$ percent.

Suppose that there is a shock to world food prices, say a one percent increase in $z_{t}^{*}$. Under flexible prices, that shock can be accommodated by only relative price movements, with no changes in home output, if $\eta=1 / \sigma$. In that case, 21 says that the terms of trade $q_{t}^{n}$ would increase by one percent. Since $x_{t}=(1-\alpha) q_{t}-z_{t}^{*}$, the real exchange rate would then fall by $\alpha$ percent. But, as we have just seen, this would have no effect on demand if $\eta=1 / \sigma$. If $\eta>1 / \sigma$, however, substitution effects would prevail and the fall in the real exchange rate would result in an increase in demand. In that case, the accommodation of the shock requires an increase in the natural rate of output. Note the strength of this would depend not only on $\eta-1 / \sigma$ but also on $\alpha$ and, further, on the domestic share $\omega$ in the demand for home goods. This explains why the impact of $z_{t}^{*}$ on $y_{t}^{n}$ in 26 depends on $\omega \alpha(\eta-1 / \sigma)$. 


\section{Implications for the IS and Impulse Responses}

As mentioned, the model is closed by adding a monetary policy rule and by specifying stochastic processes for the exogenous shocks. To gain insight on the transmission of the external price shock to domestic aggregates and illustrate the attendant dynamics, we solve for a linear approximation of the model assuming a standard Taylor rule and discuss the impulse-responses for shocks to the relative price of food, $z_{t}^{*}$.

\subsection{The Dynamic IS and the Natural Interest Rate}

As stressed by Woodford (2003), the model's response to a given monetary policy rule is best understood by describing the interaction between the rule's implications for the real interest rate and the natural interest rate. Hence our first task is to define the natural interest rate appropriately.

Linearizing the Euler condition 5 yields:

$$
\begin{aligned}
i_{t}-E_{t} \pi_{t+1} & =\sigma E_{t} \Delta c_{t+1} \\
& =E_{t}\left[\sigma \Delta c_{t+1}^{*}+\Delta x_{t+1}\right]
\end{aligned}
$$

where the second equality follows from linearizing the risk sharing condition 4 . This says that the real (CPI based) interest rate is given by expected consumption growth and hence, via risk sharing, by world consumption growth and expected real depreciation.

Now we can use 19 and its flexible price counterpart to derive a useful expression for the real exchange rate:

$$
\begin{aligned}
x_{t} & =x_{t}^{n}+(1-\alpha)\left(q_{t}-q_{t}^{n}\right) \\
& =x_{t}^{n}+(1-\alpha) \Theta \widetilde{y}_{t}
\end{aligned}
$$

where $\widetilde{y}_{t}$ is, as before, the output gap, and $x_{t}^{n}$ is the natural (flexible price) exchange rate. Note that the latter is exogenous.

Combining the preceding expressions,

$$
i_{t}-E_{t} \pi_{t+1}=E_{t}\left[\sigma \Delta c_{t+1}^{*}+\Delta x_{t+1}^{n}+(1-\alpha) \Theta \Delta \widetilde{y}_{t+1}\right]
$$

This relates the real interest rate to the expected change in the output gap, plus the exogenous variables $\Delta c_{t+1}^{*}$ and $\Delta x_{t+1}^{n}$. One could define a natural interest rate by the term $\sigma \Delta c_{t+1}^{*}+\Delta x_{t+1}^{n}$, but it is more intuitive to rewrite this in terms 
of domestic inflation instead of CPI inflation, since the NK Phillips curve depends on the former. To do this, use

$$
\begin{aligned}
\pi_{t} & =\pi_{h t}+\alpha \Delta q_{t} \\
& =\pi_{h t}+\alpha\left[\Delta q_{t}^{n}+\Theta \Delta \widetilde{y}_{t}\right]
\end{aligned}
$$

to get

$$
\begin{aligned}
i_{t}-E_{t} \pi_{h t+1} & =E_{t}\left[\sigma \Delta c_{t+1}^{*}+\Delta x_{t+1}^{n}+(1-\alpha) \Theta \Delta \widetilde{y}_{t+1}+\alpha\left(\Delta q_{t+1}^{n}+\Theta \Delta \widetilde{y}_{t+1}\right)\right] \\
& =E_{t}\left[\sigma \Delta c_{t+1}^{*}+\Delta q_{t+1}^{n}-\Delta z_{t+1}^{*}+\Theta \Delta \widetilde{y}_{t+1}\right]
\end{aligned}
$$

where we have used $x^{n}+\alpha q^{n}=q^{n}-z^{*}$. The LHS is the PPI-based real interest rate.

Defining now the natural (real) interest rate:

$$
r_{t}^{n}=E_{t}\left[\sigma \Delta c_{t+1}^{*}+\Delta q_{t+1}^{n}-\Delta z_{t+1}^{*}\right]
$$

the previous expression can be rewritten in the form:

$$
\widetilde{y}_{t}=-\frac{1}{\Theta}\left[i_{t}-E_{t} \pi_{h t+1}-r_{t}^{n}\right]+E_{t} \widetilde{y}_{t+1}
$$

which corresponds to the dynamic IS curve of Woodford (2003) and Gali (2008). As stressed by those authors, this equation says that the output gap is given by the interaction between a real interest rate and its natural counterpart. Rewriting it as

$$
\widetilde{y}_{t}=-\frac{1}{\Theta} \sum_{j=0}^{\infty} E_{t}\left[i_{t+j}-E_{t+j} \pi_{h t+j+1}-r_{t+j}^{n}\right]
$$

(under the assumption that the infinite sum converges) stresses that the output gap falls when the discounted sum of current and expected real interest rates exceeds the corresponding sum for the natural interest rates. In this sense, high real interest rates are contractionary; but, notably, what matters is not only the current value of the real interest rate, but also the expectation of all its future values.

\subsection{Policy and Impulse Responses}

Given the behavior of real interest rates, the IS curve 27 gives the behavior of the output gap, and the Phillips curve 25 the behavior of PPI inflation. To close the model, consider a PPI based Taylor rule:

$$
i_{t}=\phi_{y} \tilde{y}_{t}+\phi_{\pi} \pi_{h t}
$$


We will focus on the impulse response to a shock to the relative price of food, $z_{t}^{*}$. It is best to start with tracing the effect on the natural levels of output and the terms of trade, given by 21 and 23. Ignoring irrelevant constants:

$$
\begin{aligned}
y_{h t}^{n} & =\varrho_{y} z_{t}^{*} \\
q_{t}^{n} & =\varrho_{q} z_{t}^{*}
\end{aligned}
$$

where

$$
\varrho_{y}=\frac{\Theta[\omega \alpha(\eta-1 / \sigma)]}{(\varphi+\Theta)}
$$

and

$$
\varrho_{q}=\frac{\Theta\left[1+\varphi\left(\frac{\omega}{\sigma}+(1-\omega) \gamma\right)\right]}{(\varphi+\Theta)}
$$

As noticed at the end of the previous section, $\varrho_{y}>0$ and $\varrho_{q}<1$ when $\eta>1 / \sigma$; the opposite is also true. If $\eta=1 / \sigma, \varrho_{y}=0$ and $\varrho_{q}=1$, so it is easiest to start with this case. Then $q_{t}^{n}=z_{t}^{*}$, so that the natural interest rate does not change with the $z^{*}$ shock. Now, if the real interest rate is also expected to remain constant at all times, the dynamic IS curve implies that the output gap remains at zero. Then the Phillips curve implies that domestic inflation must also remain at zero. Finally, the PPI based Taylor rule implies that the nominal interest rate is also kept at zero, which validates the conjecture that the real interest rate remains constant.

The key to understand this result is, again, to consider the impact on the demand for home output of a change in the real exchange rate given the world's relative price of the home good. Since $x_{t}^{n}=-\alpha q_{t}^{n}=-\alpha z_{t}^{*}$, the real exchange rate must appreciate. Keeping the the world's relative price of the home good fixed, this appreciation reduces the domestic relative price of home goods, and increases demand with elasticity $\eta$. On the other hand, risk sharing implies that the real appreciation must reduce domestic consumption, with elasticity $1 / \sigma$. If $\eta=1 / \sigma$ these effects exactly cancel each other, and the real appreciation has no effects on demand if other relative prices are kept unchanged.

The same reasoning implies that if $\eta>1 / \sigma$ there will be an increase in the demand for home goods at unchanged relative prices. Hence domestic output and the output gap will expand, domestic inflation will be positive, and the nominal interest rate must go up. This can be seen in an alternative way: If $\eta>1 / \sigma$, then $\varrho_{q}<1$, so an increase in today's relative price of food increases the natural interest rate. There are two effects at work. An increase in $z_{t}^{*}$ implies that $E_{t} \Delta z_{t+1}^{*}$ 
is negative, because of mean reversion. This means that, given the expected path of the natural terms of trade, there has to be an expected real depreciation (that is, $E_{t} \Delta x_{t+1}$ increases). The anticipated depreciation leads to anticipated consumption growth, via risk sharing: this increases the natural interest rate. The counterbalancing effect is that the negative $E_{t} \Delta z_{t+1}^{*}$ leads to changes in $E_{t} \Delta q_{t+1}^{n}$ of the same sign, that is, an expected improvement over time of the natural terms of trade. This leads to an expected real appreciation and, via international risk sharing, a fall in expected consumption growth, or a lower natural interest rate. The first effect dominates if $\eta>1 / \sigma$; in this case, the natural interest rate increases at all horizons. Then the IS curve 28 implies that the output gap must increase, the Phillips curve implies that domestic inflation increases, and the policy rule yields higher nominal interest rates. The reasoning is the opposite if $\eta<1 / \sigma$.

A calibrated example illustrates and confirms the analysis. Baseline parameters are given by Table 4 and a steady-state ratio of food expenditures to consumption set to $25 \%$ so that $\omega=0.75^{10}$. The elasticity of intratemporal substitution $\eta$ between food and non-food goods is allowed to vary between 0.25 and 2 , and the coefficient of risk aversion, $\sigma$, is set to 2 . The remaining parameter choices in Table 4 are similar to the ones found in Gali and Monacelli (2005) and de Paoli (2009) as well other studies.

Figure 4 displays impulse responses for the PPI rule. The responses for the output gap, PPI inflation, the nominal interest rate, the terms of trade, the real exchange rate, and natural output are exactly as expected given our analysis. The responses of the other variables follow easily. Of particular interest is the behavior of the nominal exchange rate, which follows:

$$
\Delta s_{t}=\pi_{h t}+\Delta q_{t}-\Delta z_{t}^{*}
$$

If $\eta=1 / \sigma$, as we have seen, $q_{t}^{n}=z_{t}^{*}$. Let $t=0$ be the period of the initial shock. Since a $z^{*}$ shock has no effect on the output gap or domestic inflation in that case, $q_{0}=z_{0}^{*}$ and $\Delta s_{0}=0$. If, say, $\eta>1 / \sigma, \varrho_{q}<1$, but the output gap and domestic inflation increase. So $q_{0}$ must jump up, on impact. Also on impact, $\Delta z_{0}^{*}=1$. The increase in domestic inflation is more than compensated by the negative effect of the term $\Delta q_{0}-\Delta z_{0}^{*}=\Theta \Delta \widetilde{y}_{0}+\left(\varrho_{q}-1\right) \Delta z_{0}^{*}$, so the exchange rate jumps down. In subsequent periods $t=1,2, \ldots, \Delta q_{t}$ becomes negative as the terms of trade adjust to their steady state value. However, $\Delta q_{t}-\Delta z_{t}^{*}=\Delta q_{t}^{n}+\Theta \Delta \widetilde{y}_{t}-\Delta z_{t}^{*}=$ $\Theta \Delta \widetilde{y}_{t}+\left(\varrho_{q}-1\right) \Delta z_{t}^{*}$. The expected change in the nominal exchange rate is then

\footnotetext{
${ }^{10}$ Based on cross-country data underlying Rigobon (2008), as kindly supplied by the author.
} 
affected positively by higher domestic inflation and the expected mean reversion of the food price shock (the $\left(\varrho_{q}-1\right) \Delta z_{t}^{*}$ term), but negatively by the expected fall in the output gap (the $\Theta \Delta \widetilde{y}_{t}$ term). In figure 4 the former effect dominates the latter, so the change in the nominal exchange rate becomes positive but small in periods $t \geq 1$.

Finally, it is also worth noticing that, in the case $\eta=1 / \sigma, x_{t}^{n}=-\alpha z_{t}^{*}$, as we have seen. Then international risk sharing implies that domestic consumption must fall in response to the real appreciation. This underscores the fact that, even in a flexible price world, our model is quite different from previous ones because food price shocks sever the links between the real exchange rate and the terms of trade.

Now let us consider a CPI rule:

$$
i_{t}=\phi_{y} \tilde{y}_{t}+\phi_{\pi} \pi_{t}
$$

For comparison, assume that the coefficients of the rule are the same as those of the PPI rule. Now, since $\pi=\pi_{h}+\alpha \Delta q$, we can rewrite the rule as:

$$
\begin{aligned}
i_{t} & =\phi_{y} \tilde{y}_{t}+\phi_{\pi} \pi_{h t}+\phi_{\pi} \alpha \Delta q_{t} \\
& =\phi_{y} \tilde{y}_{t}+\phi_{\pi} \pi_{h t}+\phi_{\pi} \alpha \Delta q_{t}^{n}+\alpha \phi_{\pi} \Theta \Delta \widetilde{y}_{t} \\
& =\phi_{y}(1+\alpha \Theta) \tilde{y}_{t}-\alpha \phi_{\pi} \Theta \widetilde{y}_{t-1}+\phi_{\pi} \pi_{h t}+\phi_{\pi} \alpha \Delta q_{t}^{n}
\end{aligned}
$$

This emphasizes that the CPI rule will differ from the PPI rule in making the interest rate react to (exogenous) changes in the terms of trade plus (endogenous) changes in the output gap (over and above those prescribed by the original rule). From the last line of the above expression, it can be seen that this in turn implies that, on impact, the CPI rule will react more strongly to the output gap than the PPI rule.

To understand the difference this makes, consider again the case $\eta=1 / \sigma$, so that a shock to $z^{*}$ does not affect the output gap nor domestic inflation under a PPI rule. Also, the natural interest rate is not affected by the shock in this case. However, the natural terms of trade must change, since $q_{t}^{n}=z_{t}^{*}$. This implies that $\Delta q_{t}^{n}>0$, and $E_{t} \Delta q_{t+j}^{n}<0, j=1,2, \ldots$ Keeping the output gap and domestic inflation constant, this would mean that $i_{t}$ would increase on impact but also that all expected future interest rates would fall. The dynamic IS then implies that this is likely to be expansionary, and the Phillips curve implies that domestic inflation is likely to increase. 
Figure 5 displays impulse responses for the CPI rule. For the case $\eta=1 / \sigma$, the figures confirm the discussion in the previous paragraph. The other cases are just a mixture of this case and the results for the PPI rule.

Note that our discussion explains how the CPI rule leads to a jump in the output gap in spite of an increase in the interest rate on impact. Also, the fact that the nominal interest rate goes back to almost zero after the initial period becomes intuitive.

Finally, consider the behavior of the nominal exchange rate under the CPI rule. Assuming $\eta=1 / \sigma$ once more, $q_{t}=q_{t}^{n}+\Theta \widetilde{y}_{t}=z_{t}^{*}+\Theta \widetilde{y}_{t}$, which means that the terms of trade will be higher than with a PPI rule because of the CPI rule implies a positive output gap, as explained. The expression for the nominal exchange rate change becomes $\Delta s_{t}=\pi_{h t}+\Delta q_{t}-\Delta z_{t}^{*}=\pi_{h t}+\Theta \Delta \widetilde{y}_{t}$, which is positive for all $t$. Note that this explains why $\Delta s$ is much larger at $t=0$ than for $t \geq 1$ : this is because $\Delta \widetilde{y}_{t}$ is positive for $t=0$ but negative afterwards. This is all consistent with the various panels in Figure 5. The cases with a CPI rule and $\eta \neq 1 / \sigma$ are now straightforward after taking into account the induced responses of the output gap and domestic inflation, discussed already.

\section{Welfare and Policy Comparisons}

As already mentioned, previous work in closed as well as small open economies generally find that PPI or "core" inflation targeting is superior, in terms of welfare, than CPI inflation targeting or an exchange rate peg. Further, there is consensus that this is always the case when all elasticities are one, i.e. preferences are CobbDouglas (Gali, 2008). Finally, between CPI targeting and exchange rate pegging rules, the latter has been found to generate higher welfare levels (cf. de Paoli, 2009). This section examines whether these results still hold in a small open economy subject to shocks to the world relative price of food, over and above the usual shocks to domestic productivity and interest rates.

One key difference between our model and previous ones is easiest to illustrate in the benchmark case of Cobb-Douglas preferences and fully flexible prices. Consider an external shock, that is, a shock to either $c_{t}^{*}$ or $z_{t}^{*}$. As seen above, when $\eta=\gamma=1 / \sigma$ natural output (and also actual output, since prices are flexible) does not respond to either shock. From subsection 4.2 we also know that $\Delta q_{t}=\Delta q_{t}^{n}=$ $\Delta z_{t}^{*}$ and, since $x_{t}=(1-\alpha) q_{t}^{*}$, the real exchange will move by $\Delta x_{t}=-\alpha \Delta z_{t}^{*}$.

Risk sharing then implies that the response of home consumption is given by $\Delta c_{t}=-\alpha \Delta z_{t}^{*} / \sigma+\Delta c_{t}^{*}$. This is different from zero provided that $\Delta c_{t}^{*} \neq \alpha \Delta z_{t}^{*} / \sigma$. 
More generally, when prices are sticky and $\eta=\gamma=1 / \sigma$, it is also straightforward to show that the CPI rule will typically entail less RER and consumption volatility for a given $\mathrm{z}^{*}$ shock relative to PPI targeting even when all elasticities are one. ${ }^{11}$ Since consumption has a key bearing on utility, it is no longer warranted that PPI targeting will be the dominant policy rule even under this very particular parametrization, once $z^{*}$ shocks are non-trivial.

In what follows, we examine the relative superiority of CPI targeting, PPI targeting, and exchange rate pegging, under general parameter configurations and show how the attendant welfare ranking depends on how these policy rules affect the variances and co-variances of key relative prices.

\subsection{A Second Order Approximation to Welfare}

Evaluation of the welfare implications of monetary policy can be based on a second order approximation of the utility function of the representative agent, here the expected utility function $E \sum \beta^{t} U_{t}$. Following Gali (2008) and Woodford (2003), one can show (see Appendix 3) that the relevant part of the utility function is:

$$
\begin{aligned}
U_{t}= & E \sum_{t=0}^{\infty} \beta^{t}\left\{\frac{C^{1-\sigma}}{\varsigma}\left(c_{t}+\frac{1-\sigma}{2} c_{t}^{2}\right)-N^{1+\varphi}\left[y_{h t}\right.\right. \\
& \left.\left.+\frac{1+\varphi}{2}\left(y_{h t}-a_{t}\right)^{2}+\Theta \pi_{h t}^{2}\right]\right\}+ \text { t.i.p. }
\end{aligned}
$$

where t.i.p. stands for terms independent of policy.

As it is now well know, a difficulty emerges because of the presence of the linear terms $c_{t}$ and $y_{h t}$, which mean that a correct second order approximation to $U_{t}$ cannot be based on a first order approximation to the equilibrium equations (see Woodford 2003, chapter 6). One alternative is to solve for a second order approximation to equilibria, and use the resulting expressions to eliminate the linear terms $c_{t}$ and $y_{h t}$ from the previous expressions. This is the strategy of e.g. Benigno and Benigno (2003) and de Paoli (2009). In our case, that route leads to complicated expressions that give little insight (at least to us). Therefore, we compute second order approximations to welfare numerically in the next subsection.

\footnotetext{
${ }^{11}$ The respective derivations are available from the authors upon request.
} 
A little work, however, yields some information about the policy tradeoffs in our model and the differences we find relative to other previous work. The preceding expression for $U_{t}$ reveals that the welfare associated with a given policy depends positively on the expected level of consumption, negatively on the expectation of output (labor supply), and negatively on the volatility of consumption, output, and inflation. Now, noting that the risk sharing condition

$$
c_{t}=c_{t}^{*}+\frac{1}{\sigma} x_{t}
$$

is an exact relation, it follows that the expectation of $c_{t}$ increases with the expectation of the real exchange rate $x_{t}$. Hence, there is an incentive for home policy to engineer a real depreciation, on average.

On the other hand, if the real exchange rate is expected to be weak, the home good might be expected to be relatively cheap, and hence expected labor supply may increase, reducing utility. To elucidate this issue, one can use 7 and (14) to solve for a second order approximation of $y_{h t}$ in terms of the first and second moments of $x_{t}$ and $z_{t}^{*}$. In this approximation, the covariance term $E x_{t} z_{t}^{*}$ appears with a sign that depends on the parameters of the model. For example, in the less unwieldy case of equal (but not necessarily unity) elasticities $(\eta=\gamma=1 / \sigma)$, this yields:

$$
\begin{aligned}
Y_{h t} \equiv & 1+\left(\frac{\eta}{1-\alpha}\right) x_{t}+\frac{\alpha \eta}{1-\alpha} z_{t}^{*} \\
& +\frac{1}{2} x_{t}^{2}\left(\eta\left(\frac{\alpha}{1-\alpha}\right)^{2}+3 \eta^{2}\left(\frac{\alpha}{1-\alpha}\right)+\eta(\eta-1)\right) \\
& +\frac{1}{2}\left(\eta\left(\frac{\alpha}{1-\alpha}\right)^{2}-\eta^{2}\left(\frac{\alpha}{1-\alpha}\right)\right) z_{t}^{* 2} \\
& +\left(\eta\left(\frac{\alpha}{1-\alpha}\right)^{2}+\eta^{2}\left(\frac{\alpha}{1-\alpha}\right)+\frac{\alpha \eta(1-\eta)}{1-\alpha}\right) x_{t} z_{t}^{*}
\end{aligned}
$$

This expression shows that $Y_{h t}$ increases with the level of $z_{t}^{*}$ and $x_{t}$ and with the variance of the real exchange rate. Hence a policy rule that delivers more real exchange volatility relative to others (as such as PPI vs. CPI targeting) will be associated, all else constant, with higher $Y_{h t}$, as seen in previous work (cf. de Paoli, 2009). What is different here from models in which the terms of trade and the real exchange rate move in the same direction is the presence of the covariance term 
$E x_{t} z_{t}^{*}$. Even though it has an unambiguously positive coefficient, this covariance can be larger or smaller, depending on the policy rule. In fact, our discussion of impulse responses indicate that this covariance is likely to be negative under both PPI and CPI targeting, leading to lower output. This means that there are non-trivial trade-offs associated with the way alternative policies exploit the covariance of the real exchange rate and global relative prices. Under more general parametrizations, welfare may increase or decrease if monetary policy results in a larger covariance between price shocks and the real exchange rate. This effect, of course, is absent from other models, as they do not allow for shocks to world relative prices.

\subsection{Policy Rules}

As mentioned, the equilibria of our model are pinned down once a monetary policy rule is given. If monetary policy is an interest rate rule, we need to append the Euler equation 5 to the equilibrium system. The model is then closed by specifying different rules relating the domestic interest rate to other variables.

The first rule we consider is a domestic inflation (PPI) Taylor rule:

$$
\log \left(1+i_{t}\right)=\left(\rho+\phi_{\pi}\left(\Pi_{h t}-1\right)+\phi_{y}\left(y_{h t}-y_{h t}^{n}\right)+v_{t}\right)
$$

where $Y_{h t}^{n}$ is natural output ${ }^{12}$ We also study a CPI Taylor rule, given by:

$$
\log \left(1+i_{t}\right)=\left(\rho+\phi_{\pi}\left(\Pi_{t}-1\right)+\phi_{y}\left(y_{h t}-y_{h t}^{n}\right)+v_{t}\right)
$$

where $\Pi_{t+1}=P_{t+1} / P_{t}$.

Finally, we consider a nominal exchange rate peg rule, in which the monetary authority fixes the nominal exchange rate $S_{t}$ to a constant $S$. Then the real exchange rate must satisfy $X_{t}=S P_{t}^{*} / P_{t}$, which implies:

$$
X_{t} P_{h t}=S P_{t}^{*}\left(\frac{P_{h t}}{P_{t}}\right)
$$

where by definition,

$$
\Pi_{h, t}=\frac{P_{h t}}{P_{h, t-1}}
$$

\footnotetext{
${ }^{12}$ Natural output is obtained, together with other natural variables, by setting $\theta=0$ in equation (12) and substituting in the equations in Appendix 1. This yields a static 4-equation system which can be solved for $C_{t}^{n}, Q_{t}^{n}, X_{t}^{n}$, and $Y_{h t}^{n}$ given the exogenous variables $Z_{t}^{*}, C_{t}^{*}$, and $A_{t}$.
} 
Introducing these equations in the system, and withdrawing the Euler equation in the monetary policy rule that we had for the CPI and PPI cases, we are now left with eleven equations in the eleven variables: $C, X,\left(P_{h} / P\right), Y_{h},\left(\bar{P} / P_{h}\right)$, $\Pi_{h}, Z, H, M, F$ and $P_{h}$ Having the level of $P_{h}$ as a new variable to solve for, and with a constant $S$, the domestic price level is pinned-down by introducing a stochastic process the (log of) world price, given by: $p_{t}^{*}=a+b p_{t-1}^{*}+\epsilon_{t}$, where $\epsilon_{t}$ is white noise.

\subsection{Policy Rankings}

We use the numerical procedures and programs of Schmitt Grohe and Uribe (2004) to calculate the utility associated with each of the three policy rules under study. We follow Schmitt-Grohe and Uribe (2007) and Wang (2006) in computing welfare comparisons that are "conditional " on the same starting point which, as in these previous studies, is the non-stochastic steady state. Besides the obvious theoretical appeal of this metric, Wang (2006) shows that it also simplifies the computational burden considerably. Specifically, he shows that the second order approximation of the instantaneous discounted value of the representative agent's welfare, conditional on such a starting point, has the form:

$$
V_{t}=V+\frac{1}{2} g_{\sigma \sigma}(\bar{x}, 0) \sigma
$$

where $V$ is steady state conditional utility, $x$ is a vector of the model state variables at the non-stochastic steady state, $g_{\sigma \sigma}$ is the second derivative of the $g$ function with respect to the variance of the shocks (once the system is set so that the vector of control variables takes the form $\left.y_{t}=g\left(x_{t}, \sigma\right)\right)$, and $\sigma$ is a scalar governing the variance of the shocks. Intuitively, given each policy, the last term in the above equation captures the adjustment of initial positions due to uncertainty.

Computationally, this calculation amounts to a simple addition of a control variable $V_{t}$ to the system of equations entering the Schmitt Grohe and Uribe algorithm, which will evolve according to the law of motion $V_{t}-\beta V_{t}=U\left(C_{t}, N_{t}\right)$. Then, the relative welfare loss of policy rule $i$ relative to policy rule $j$, expressed in percentage units of steady state consumption, will be given by $100 \times\left(1-e^{(1-\beta)\left(V_{0}^{i}-V_{0}^{j}\right)}\right)$. 


\subsection{Calibration}

In the calibrations that follows, we examine the net balance of the policy trade-offs on welfare using benchmarks from a prototype emerging market (Chile) as well as other international data to calibrate the stochastic processes for the relative world price of food, TFP, domestic and external interest rate shocks. We also assume Taylor rule coefficients that are close to those estimated in practice for economies operating inflation targeting regimes. We evaluate the robustness of the results for a wide range of alternative parametrizations, including that of the standard deviation and persistence of the various shocks as well as various combinations of the intra-temporal elasticity of consumption, which we let take on values between 0.25 and 4, and the coefficient of risk aversion (the inverse of the inter-temporal elasticity), which we let take on values between 0.5 and 4 , consistent with the range of estimates found in empirical macro studies.

Baseline parameter values are reported in Table 5. All parameters are computed on a quarterly frequency and the ratio of home good consumption to income in steady-state $(\omega)$ is set to 0.75 . We show later the effects of varying it within a wide but still reasonable range (0.6 to 0.9$)$. Since in the non-linear representation of the model's steady state $\omega$ is a function of $\varsigma, \kappa$, and $Y^{*}$, we must fix only two of these three parameters and allow one of them to adjust across distinct combinations of the substitution elasticities. Since we have no evidence of what a realistic calibration for $\varsigma$ might be (something complicated by its dependence on the unit of measurement with which one evaluates the weight of consumption and leisure in utility), we fix both world income $Y^{*}$ and the initial level of net foreign assets that pins down $\kappa$, and let $\varsigma$ adjust so as keep $1-\omega$ fixed. The other parameter of interest is world consumer price index. Initially we fix it to unity but let it later to evolve according to a stochastic process with considerable persistence $(\rho=0.99)$ and (quarterly) standard deviation of $1.3 \%$, as obtained from a quarterly $\operatorname{AR}(1)$ regression of an unweighted average of advanced countries (G-8) PPIs during the 1990-2008 period.

Critical to our results is the volatility of world food prices relative to world CPI. We parameterize $z^{*}$ as displaying a conditional (quarterly) standard deviation of $4.5 \%$ and an $\mathrm{AR}(1)$ coefficient of 0.85 , consistent with regressions of the IFSIMF index of food commodity prices relative to world (G-8) WPI between 1990 and 2008. Based on estimates using Chilean data, the standard deviation of productivity shocks is set at $1.2 \%$ per quarter and its $\mathrm{AR}(1)$ coefficient at 0.7 . The latter is very similar to one used by Gali and Monacelli (2005) using Canadian data, whereas their reported standard deviations of TFP shocks for Canada is 
nearly half $(0.7 \%)$, consistent with the fact that output in the Chilean economy has been about twice or so more volatile than in Canada. Further below, we also examine the robustness of the results to changes in such TFP parameters. Finally, we calibrate $v_{t}$ by running a Taylor rule-type regression with Chilean data from 1991 to 2008 . We obtain a standard deviation of $v_{t}$ of $0.62 \%$ per quarter and and $\mathrm{AR}(1)$ coefficient of 0.6. Again, we examine the sensitivity of results to alternative calibrations. In calibrating labor supply $(1 / \varphi)$ and export price $(\gamma)$ elasticities, we take values used in other studies (e.g. Bergin et al, 2007; Gali, 2008) with acknowledgement that they appear to vary widely in the data. So, we let their range vary from 1 (benchmark) to $1 / 3$ and from 1 to 5 , respectively.

\subsection{Results}

We start with the baseline parametrization in Table 6 and with the coefficient on the output gap set to zero, so that we have "strict" (as opposed to the so-called "flexible") inflation targeting. As with all subsequent welfare ranking tables, we report the values of $\tau$ for pair-wise comparisons between PPI targeting ("rule 1), CPI targeting ("rule 2") and the exchange rate peg ("rule 3), and the resulting overall relative rankings between the three rules. The table allows for different values of $\eta$ and $\sigma$.

As usual with welfare comparisons, $\tau$ values are generally low, albeit generally of an order of magnitude higher than those featuring in Lucas's (1987) classic illustration of the welfare cost of business cycles. Be that as it may, the conventional wisdom on PPI dominance is clearly overruled. The ranking at the bottom of Table 6 identifies CPI targeting ("rule 2") as the best rule for the majority of $\eta-\sigma$ configurations, and particularly for the arguably more realistic cases where $\eta$ is low and $\sigma$ is high.

Our allowance for international relative price shocks (here food price shocks) is crucial in accounting for this result. Tables 7 and 8 provide some insight. Table 7 keeps the same parametrization as in Table 6 but sets the variance of world food price shocks to near zero. Then we recover the results of previous authors: either the exchange rate peg or PPI targeting dominates. In particular, for the unit elasticity case $(\eta=\sigma=\gamma=1$ ), it can be shown (by combining 13, 4 with $\kappa=1$ and a fixed $\omega$ ) that trade will be balanced at all times. With the variance of $z^{*}$ shocks negligible, our economy then becomes isomorphic to the Gali-Monacelli benchmark, for which they show analytically that PPI is the dominant policy rule. This is precisely what our numerical results show. So, if relative food price shocks 
are negligible, PPI is the dominant rule when agents are risk averse and, more generally, when intra-temporal substitution elasticities are not too low.

To gain further insight into this result, Table 8 computes means and standard deviations for the model variables that have a key bearing on welfare ${ }^{13}$. We do so for the case in which only food shocks are present, as well as for the cases where only productivity and only monetary policy shocks are present. Columns (1) to (6) show that, if only food price shocks are present, CPI targeting yields lower RER and consumption volatility, as well as lower output (and hence lower effort) and a higher consumption to output ratio. The table also points to what is behind such a higher $\mathrm{C} / \mathrm{Y}$ ratio, namely a more appreciated $\mathrm{RER}$ on average ( $0.32 \%$ above steady state).

Why CPI targeting tends to produce a more appreciated RER under food price shocks is apparent from the expression for home pricing equation derived in Appendix 2. As PPI targeting seeks to minimize home price volatility and its covariance with $z^{*}$ shocks (and hence with the CPI), then $\bar{P}_{h t}$ will be lower; all else constant, this implies a weaker RER. In contrast, CPI tends to be more accommodative with home price volatility and lets it co-vary more in tandem with $z^{*}$ shocks (and hence with the CPI). That entails a stronger RER which allows the country to exploit its terms of trade externality, leading to a higher consumption to output ${ }^{14}$. So, the welfare superiority of CPI targeting shown in Table 6 appears to reflect that rule's edge in generating more consumption relative to output and lower consumption volatility relative to both PPI and PEG rules, at least when only food price shocks are present.

Table 8 also indicates, consistent with our discussion, why CPI is less attractive if only productivity or monetary shocks are present. In the productivity shockonly case, PPI targeting produces the lowest consumption and real exchange rate volatility, as well as (marginally) higher $\mathrm{C} / \mathrm{Y}$. So, in a world where domestic productivity are of overwhelming importance, PPI targeting ought to be preferred. Again, this can be explained with referring to the relationship between the level of the home price index and the covariance between income and marginal cost shocks under Calvo-pricing, which we flesh out in Appendix 2. With productivity shocks only, that covariance will be negative. Because the overriding goal of PPI rule is to stabilize $P_{h}$, PPI targeting will react in a stronger procyclical manner

\footnotetext{
${ }^{13}$ These moments are computed by feeding the second-order approximation solution to the model with a 20,000 random draws of $\mathrm{z}^{*}$, a, and $\mathrm{v}$ shocks.

${ }^{14}$ This is shown for $\sigma=2$ or $\sigma=4$ in the table; further parametrizations available from the authors upon request.
} 
to productivity shocks than CPI targeting. This will prevent marginal costs from falling as much as it would so that covariance will be less negative than under CPI targeting. So, as per equation 30, the home price level will be higher, and hence the RER will be more appreciated under a PPI rule. With a more appreciated RER, the ratio of $\mathrm{C} / \mathrm{Y}$ will be higher, all else constant. This is indeed what columns 7-9 of Table 8 show. So, only when food price shocks reenter the picture, as in the last three columns of Table 8 , do the reasons for CPI dominance reemerge.

Table 9 examines what happens to relative welfare rankings if the volatility of monetary policy (interest rate) shocks doubles, from $0.6 \%$ per quarter to $1.2 \%$ per quarter, under the baseline parametrization of Table 6. As expected, the result is to increase the attractiveness of the peg rule. As monetary policy shocks become larger, the numerical magnitudes of welfare differences also grow larger, in some cases reaching $0.6 \%$ of steady state consumption.

Tables 10 repeats the exercise for domestic TFP shocks. For the reasons already discussed, this increases the attractiveness of PPI relative to other rules. Yet, keeping the standard deviation of $z^{*}$ shocks at non-trivial levels $(4.5 \%$ a quarter), this does not translate into far-reaching PPI dominance.

Table 11 goes back to the baseline specification of Table 6 except that we have now a more aggressive policy reaction to inflation, with $\phi_{\pi}=3.0$. What this does is basically to increase the attractiveness of exchange rate pegs. But focusing only on the CPI-PPI trade-offs, a more hawkish anti-inflation stance increases the dominance of PPI over CPI, although the welfare gaps are particularly tiny for realistic values of $\sigma$ (i.e. above 1 ).

Table 12 moves away from strict inflation targeting by placing some weight on output stabilization. This reduces even further the numerical gaps between rules: with (the correct measure of) output weighting on monetary policy decisions, all the rules become more similar in terms of welfare losses, with the differences between CPI and PPI shrinking considerably for higher values of $\eta$.

Table 13 moves the export price elasticity parameter from $\gamma=1$ to $\gamma=5$, consistent with some empirical work (see Harrigan, 1993). One might expect that this would decrease the attractiveness of CPI targeting under $z^{*}$ shocks, since a higher substitutability between domestic and foreign non-food goods offers less scope for the small open economy to exploit its terms of trade externality. However, a higher $\gamma$ also implies that greater RER volatility brings about greater domestic output volatility (as domestic goods become more substitutable with foreign ones) and hence higher employment volatility, which hurts welfare (see equation 31). Overall, the upper panel in Table 13 clearly indicates that the 
latter effect dominates: CPI targeting becomes even more attractive than PPI targeting, with the numerical welfare gaps $(\tau)$ being not so negligible at times. By the same token, CPI beats PEG more often, implying that the dominance of CPI targeting increases relative to the baseline of $\gamma=1$.

Table 14 differs from Table 6 in lowering the labor supply elasticity to a third. As can be gleaned from equation (29), a higher $\varphi$ increases the weight of disutility associated with higher employment levels and volatility. Combining this with the simulation results of Table 8, it is clear why a higher $\varphi$ reduces the attractiveness of the peg relative to both CPI and PPI.

Thus far, from Table 6 to 14, we have set the volatility of the world price $p^{*}$ to zero, thus increasing the stabilization properties of exchange rate pegging . Table 15 changes this by letting $p^{*}$ be driven by a very persistent stochastic process, with a realistic quarterly variance of $1.3 \%$. This results in greater dominance of CPI and PPI relative to the exchange rate peg, with CPI becoming more dominant for higher risk aversion $\sigma$ when, as discussed, the higher RER volatility engendered by PPI targeting hurts welfare more strongly.

As a final experiment, Table 16 takes the benchmark case of Table 6 but changes $\omega$ to 0.6 , hence letting the economy be more open in steady state relative to the baseline $\omega=0.75$. This high openness scenario entails even greater CPI rule dominance, especially for $\sigma$ above 0.5 . No less importantly, for the empirically more realistic combination of higher $\sigma$ and lower $\eta$, the welfare gains of CPI relative to PPI are not so trivial, ranging between 0.33 percent $(\sigma=2$ and $\eta=$ $0.25)$ and 0.62 percent $(\sigma=2$ and $\eta=0.75)$ of steady state consumption.

\section{Conclusion}

Wide fluctuations in the global relative price of primary commodities have been long-standing phenomena (Jacks, O'Rourke, and Williamson 2009). Among primary commodities, food price volatility has been particularly pronounced, typically spiking up in the run up to global inflationary spurts. Yet, its macroeconomic transmission and implications for monetary policy in small open economies have not been previously examined in the growing literature on monetary DSGE models. Given the potentially important role of food price shocks in deviating inflation from target in these economies, and in light of concerns that food price pressures may re-emerge once the global economic recovery strengthens, it seems urgent to 
fill this literature gap. ${ }^{15}$

This paper has sought to do so in the context of a canonical small open economy model, modified by the introduction of an imported good (food) with a weight in utility that is sizeable and larger than that of the rest of the world, and with a fluctuating world relative price. The model also takes into account some wellknown features of food in utility, such as its low intra-temporal substitution with other consumption goods, and explores quantitatively attendant implications for monetary transmission and policy targeting under a wider set of parametrization than previous studies.

Some notable results emerge, of both analytical and quantitative nature. First, we show that the global relative price shock opens up the possibility of opposite movements in the terms of trade (TOT) and the real exchange rate (RER). This is because if food has a higher weight in the domestic relative to the foreign consumption basket, higher world food prices tend to appreciate the RER while depreciating the terms of trade of the small net food importing open economy. This in turn has a theoretically ambiguous effect on domestic output: an adverse food price shock can be expansionary or contractionary depending on the model's parameters and the specific policy rule. This results contrasts with wisdom inherited from previous models where such global relative price shocks were absent (e.g. Cova and Sondegaard, 2004; Gali and Monacelli, 2005; de Paoli, 2009). In that case, TOT and the RER necessarily move in the same direction and their juxtaposition would imply that an adverse terms of trade shock must be unambiguously expansionary. Empirical evidence to the contrary argues in favor of our more general setting.

The second novel result is that, even under standard risk sharing and CobbDouglas preferences (when all intra- and inter-temporal elasticities equal to one), the small open economy is not isomorphic to a closed one in the sense that domestic consumption is not invariant to the world relative price shock, all else constant (including world consumption). This is because insofar as food represents a non-trivial share of the domestic consumption basket relative to the foreign counterpart, the RER moves with the exogenous relative price, and so does domestic consumption. This result is of particular importance since all previous studies agree that under Cobb-Douglas preferences the main imperfection that monetary policy should seek to mitigate is the domestic price stickiness; hence targeting domestic PPI inflation is always welfare superior to other rules. Once this full

\footnotetext{
${ }^{15}$ See, e.g., http://www.ft.com/foodprices for recent developments in world food supply and prices as well as on debate on the resurgence of food price pressures.
} 
isomorphism is broken, the superiority of PPI targeting is no longer warranted, as we illustrate by model calibrations under various alternative parametrizations.

Third, and on a broader quantitative take, we show - via both impulseresponses on the log-linearized model as well as simulations using a second-order approximation - that significant differences in the responses of macro aggregates to the food price shock arise under distinct policy rules. This is not surprising since, from a simple re-writing of the CPI targeting rule, we show how it entails a direct reaction to the terms of trade shock as well as a stronger response to impact changes in the output gap than the PPI rule. We also show that shifts in world food prices typically entail very distinct responses of the exchange rate, output and inflation relative to the more standard shocks to domestic interest rates and productivity. In particular, as domestic interest rates rise with the shock, the nominal exchange rate will depreciate (rather than appreciate on impact) in response to the monetary tightening, CPI inflation will rise, and output can go either way, as the terms of trade and the real exchange rate can move in opposite directions as discussed above. A key implication of this distinct pattern of covariances is that the welfare ranking of monetary policy rules will be very distinct from previous studies once imported price shocks are non-trivial.

In general and in contrast with previous calibrations of the canonical DSGE small open economy model, we find that CPI targeting generally dominates PPI targeting and exchange rate pegging. This is because CPI targeting tends to lower the volatility of the RER relative to PPI and appreciate the mean RER relative to both peg and PPI rules. This, in turn, allows the country to take advantage of the so-called terms of trade externality, i.e., to consume more per unit of domestic output and thus enhance welfare (given disutility of labor effort). The volatility of output and employment, however, will be higher relative to the PPI rule and so will be domestic inflation, implying that important policy trade-offs are at stake, pertaining to how the distinct policies exploit relative price covariances. We further corroborate these results by showing that if global food price volatility becomes trivial, and/or the food share in the domestic consumption basket shrinks substantially, the welfare rankings of previous studies are replicated.

A final issue is whether a higher weight on the output gap in the monetary policy reaction function could narrow or even overturn the welfare superiority of CPI relative to PPI targeting. We show that this is the case provided that the central bank uses the theoretically correct (model-based) measure of natural output. We show that such a measure for a net food importing country should include fluctuations in the terms of trade and hence in the relative world price of 
food. Once this correct measure of the output gap is introduced in the monetary policy reaction with empirically sensible weights, welfare differences between PPI and CPI targeting are narrowed and the CPI welfare superiority even overturned under certain parametrizations. A practical problem of such a reinstatement of an output-gap adjusted PPI targeting is, of course, its reliance on the correct measure of the output gap, which is known to be highly non-trivial in practice.

Our results thus shed new light on question of how far monetary policy should lean against the wind of shocks to relative world food prices. Given the general welfare superiority of broad CPI targeting and that the latter typically implies a strong reaction to imported inflation, there is a strong case against monetary policy leniency towards the imported price shock even though the economy is small and thus unable to affect world prices.

Some other policy implications follow. One is that the rationale for broad CPI targeting as currently adopted by many central banks is strenghtened once we allow for the role of food in utility. This rationale reinforces considerations related to transparency and avoidance of ad hoc criteria to define the "core" component in CPI, as well as the credibility gains that might arise from targeting a broader price index.

Second, the case provided here for CPI targeting and implicit partial offset of imported food inflation therein also rectifies some of the regressive distributional bias associated with the usual prescription that monetary policy should focus on offsetting the sticky-price distortion. To the extent that food and other commodity prices are less sticky and determined under a more competitive market structure, this prescription implies that central banks should be more lenient towards inflation or deflation in those sectors. Yet, we know that the weight of food in overall spending is higher among poorer households which are also precisely the ones with more limited access to credit markets to smooth real purchasing power fluctuations arising from shocks to relative food prices. Thus strict PPI targeting has a regressive distributional bias that CPI targeting mitigates. While a model like ours featuring identical households is not suitable to address such distributional effects on welfare, it seems important to note here that this might be an non-trivial extra benefit of CPI targeting predicated by our calibrations in a representative agent setting.

Finally, if all inflation targeting central banks follow a non-accomodative stance against such imported price shocks, this should help mitigate the externality problem associated with uncoordinated/inward oriented policy responses that typically arise when central banks target PPI or the exchange rate. Less accommodative 
policy based on broad CPI stabilization would thus be more conducive to keep global inflationary pressures in check, as well as its converse whenever commodity prices tank. 


\section{Appendix 1: Recursive Representation of the Model}

Consider the pricing function:

$$
\sum_{k=0}^{\infty} \theta^{k} E_{t}\left[M_{t, t+k} Y_{t+k \mid t}\left(\frac{\bar{P}_{t}}{P_{h t}}-\frac{\varepsilon}{\varepsilon-1} M C_{t+k \mid t} \Pi_{t, t+k}^{h}\right)\right]=0
$$

Let us write the previous expression in a recursive way:

$$
\frac{\bar{P}_{t}}{P_{h t}} J_{t}=\frac{\varepsilon}{\varepsilon-1} H_{t}
$$

where

$$
J_{t}=E_{t} \sum_{k=0}^{\infty} \theta^{k} M_{t, t+k} Y_{t+k \mid t}
$$

and

$$
H_{t}=E_{t} \sum_{k=0}^{\infty} \theta^{k} M_{t, t+k} Y_{t+k \mid t} M C_{t+k \mid t} \Pi_{t, t+k}^{h}
$$

Recall

$$
M_{t, t+k}=\beta^{k}\left(\frac{C_{t+k}}{C_{t}}\right)^{-\sigma} \frac{P_{t}}{P_{t+k}}
$$

and

to derive:

$$
Y_{t+k \mid t}=\left(\frac{\bar{P}_{t}}{P_{h t+k}}\right)^{-\varepsilon} Y_{h t+k}
$$

$$
\begin{aligned}
J_{t} & =Y_{t \mid t}+E_{t} \sum_{k=1}^{\infty} \theta^{k} M_{t, t+k} Y_{t+k \mid t} \\
& =\left(\frac{\bar{P}_{t}}{P_{h t}}\right)^{-\varepsilon} Y_{h t}+E_{t} \sum_{k=1}^{\infty}(\beta \theta)^{k}\left(\frac{C_{t+k}}{C_{t}}\right)^{-\sigma}\left(\frac{P_{t}}{P_{t+k}}\right)\left(\frac{\bar{P}_{t}}{P_{h t+k}}\right)^{-\varepsilon} Y_{h t+k} \\
J_{t} & =\left(\frac{\bar{P}_{t}}{P_{h t}}\right)^{-\varepsilon} Y_{h t}+\beta \theta E_{t}\left(\frac{C_{t+1}}{C_{t}}\right)^{-\sigma}\left(\frac{P_{t}}{P_{t+1}}\right)\left(\frac{\bar{P}_{t}}{\bar{P}_{t+1}}\right)^{-\varepsilon} J_{t+1}
\end{aligned}
$$

To express $H_{t}$ recursively, it is convenient to write:

$$
\begin{aligned}
M C_{t+k \mid t} & =\left[(1-v) \varsigma C_{t+k}^{\sigma} P_{t+k} / A_{t+k}^{1+\varphi} P_{h, t+k}\right] Y_{t+k \mid t}^{\varphi} \\
& =F_{t+k} Y_{t+k \mid t}^{\varphi}
\end{aligned}
$$


where

$$
F_{t}=(1-v) \varsigma C_{t}^{\sigma} P_{t} / A_{t}^{1+\varphi} P_{h t}
$$

so that:

$$
\begin{aligned}
H_{t} & =E_{t} \sum_{k=0}^{\infty} \theta^{k} M_{t, t+k} F_{t+k} Y_{t+k \mid t}^{1+\varphi} \Pi_{t, t+k}^{h} \\
& =F_{t} Y_{t \mid t}^{1+\varphi}+E_{t} \sum_{k=1}^{\infty} \theta^{k} M_{t, t+k} F_{t+k} Y_{t+k \mid t}^{1+\varphi} \Pi_{t, t+k}^{h} \\
H_{t} & =F_{t}\left(\frac{\bar{P}_{t}}{P_{h t}}\right)^{-\varepsilon(1+\varphi)} Y_{h t}^{1+\varphi}+\beta \theta E_{t}\left(\frac{C_{t+1}}{C_{t}}\right)^{-\sigma}\left(\frac{P_{t}}{P_{t+1}}\right)\left(\frac{\bar{P}_{t}}{\bar{P}_{t+1}}\right)^{-\varepsilon(1+\varphi)} \frac{P_{h t+1}}{P_{h t}} H_{t+1}
\end{aligned}
$$

Nine equations in the ten variables: $C, X,\left(P_{h} / P\right), Y_{h},\left(\bar{P} / P_{h}\right), \Pi_{h}, Z, H, M, F$. The system is completed with the specification of monetary policy. 


\section{Appendix 2: Relationship between Home Pricing and Covariance of Income and Cost Shocks}

$$
\begin{gathered}
L=\sum_{k=0}^{\infty} \theta^{k} E_{t}\left[M_{t, t+k} Y_{t+k \mid t}\left(\frac{\bar{P}_{t}}{P_{h t}}-\frac{\varepsilon}{\varepsilon-1} M C_{t+k \mid t}^{n}\right)\right]=0 \\
=\sum_{k=0}^{\infty} \theta^{k} E_{t}\left[M_{t, t+k}\left(\frac{\bar{P}_{t}}{P_{h t+k}}\right)^{-\varepsilon} Y_{h t+k}\left(\bar{P}_{t}-\frac{\varepsilon}{\varepsilon-1} M C_{t+k}^{n}\left(\frac{\bar{P}_{t}}{P_{h t+k}}\right)^{-\varphi \varepsilon}\right)\right]=0 \\
\sum_{k=0}^{\infty} \theta^{k} E_{t} M_{t, t+k}\left(\frac{\bar{P}_{t}}{P_{h t+k}}\right)^{-\varepsilon} Y_{h t+k} \bar{P}_{t}=\frac{\varepsilon}{\varepsilon-1} \sum_{k=0}^{\infty} \theta^{k} E_{t} M_{t, t+k} Y_{h t+k} M C_{t+k}^{n}\left(\frac{\bar{P}_{t}}{P_{h t+k}}\right)^{-\varepsilon}\left(\frac{\bar{P}_{t}}{P_{h t+k}}\right)^{-\varphi \varepsilon} \\
\sum_{k=0}^{\infty} \theta^{k} E_{t} M_{t, t+k} \frac{\bar{P}_{t}^{-\varepsilon+1}}{P_{h t+k}^{-\varepsilon}} Y_{h t+k}=\frac{\varepsilon}{\varepsilon-1} \sum_{k=0}^{\infty} \theta^{k} E_{t} M_{t, t+k} Y_{h t+k} M C_{t+k}^{n}\left(\frac{\bar{P}_{t}^{-\varphi \varepsilon-\varepsilon}}{P_{h t+k}^{-\varphi \varepsilon-\varepsilon}}\right) \\
\text { Let: } \Xi_{t, t+k}^{d}=M_{t, t+k} Y_{h t+k} P_{h t+k}^{\varepsilon} \\
\sum_{k=0}^{\infty} \theta^{k} E_{t} \Xi_{t, t+k}=\frac{\varepsilon}{\varepsilon-1} \sum_{k=0}^{\infty} \theta^{k} E_{t} M_{t, t+k} Y_{h t+k} M C_{t+k}^{n}\left(\frac{\bar{P}_{t}^{-\varphi \varepsilon-\varepsilon+\varepsilon-1}}{P_{h t+k}^{-\varphi \varepsilon-\varepsilon}}\right) \\
\sum_{k=0}^{\infty} \theta^{k} E_{t} \Xi_{t, t+k}^{d}=\frac{\varepsilon}{\varepsilon-1} \sum_{k=0}^{\infty} \theta^{k} E_{t} \Xi_{t, t+k}^{d} P_{h t+k}^{\varphi \varepsilon} M C_{t+k}^{n} \bar{P}_{t}^{-\varphi \varepsilon-1} \\
\sum_{t}^{\infty} \theta^{k} E_{t} M_{t, t+k} Y_{h t+k} P_{h t+k}^{(\varphi+1) \varepsilon} M C_{t+k}^{n} \\
\sum_{k=0}^{\infty} \theta^{k} E_{t} \Xi_{t, t+k}^{d}
\end{gathered}
$$

\section{Appendix 3: A Second Order Approximation to the Util- ity Function}

We follow Gali (2008) and Woodford (2003). Ignoring higher order terms here and in the rest of this section, a second order approximation of the consumption part is easy:

$$
\frac{C_{t}^{1-\sigma}}{\varsigma(1-\sigma)}=\frac{C^{1-\sigma}}{\varsigma(1-\sigma)}+\frac{C^{1-\sigma}}{\varsigma}\left(c_{t}+\frac{1-\sigma}{2} c_{t}^{2}\right)
$$


with lowercase letters referring to log deviations from nonstochastic steady states henceforth.

The term in labor effort is approximated as follows:

$$
\begin{aligned}
\frac{N_{t}(j)^{1+\varphi}}{1+\varphi}= & \frac{N^{1+\varphi}}{(1+\varphi)}+N^{1+\varphi}\left[n_{t}(j)+\frac{1+\varphi}{2} n_{t}(j)^{2}\right] \\
= & \frac{N^{1+\varphi}}{(1+\varphi)} \\
& +N^{1+\varphi}\left[y_{t}(j)+\frac{1+\varphi}{2} y_{t}^{2}(j)-(1+\varphi) a_{t} y_{t}(j)+\frac{1+\varphi}{2} a_{t}^{2}-a_{t}\right]
\end{aligned}
$$

The last line comes from $y_{t}(j)=n_{t}(j)+a_{t}$.

Hence,

$$
\begin{aligned}
\int \frac{N_{t}(j)^{1+\varphi}}{1+\varphi} d j= & \frac{N^{1+\varphi}}{(1+\varphi)} \\
& +N^{1+\varphi}\left[E_{j} y_{t}(j)+\frac{1+\varphi}{2} E_{j} y_{t}^{2}(j)-(1+\varphi) a_{t} E_{j} y_{t}(j)+\frac{1+\varphi}{2} a_{t}^{2}-a_{t}\right]
\end{aligned}
$$

where $E_{j} y_{t}(j)$ denotes the cross sectional average of the $y_{t}(j)^{\prime} s$. Use

$$
y_{h t}=E_{j} y_{t}(j)+\frac{1}{2}\left(1-\frac{1}{\varepsilon}\right) \operatorname{var}_{j} y_{t}(j)
$$

to second order and get:

$$
\begin{aligned}
\int \frac{N_{t}(j)^{1+\varphi}}{1+\varphi} d j= & \frac{N^{1+\varphi}}{(1+\varphi)} \\
& +N^{1+\varphi}\left[y_{h t}-a_{t}+\frac{1+\varphi}{2} y_{h t}^{2}-(1+\varphi) a_{t} y_{h t}\right. \\
& \left.+\frac{1}{2}\left(\frac{1}{\varepsilon}+\varphi\right) \operatorname{var}_{j} y_{t}(j)+\frac{1+\varphi}{2} a_{t}^{2}\right]
\end{aligned}
$$

Now,

$$
\operatorname{var}_{j} y_{t}(j)=\varepsilon^{2} \operatorname{var}_{j}\left(\log p_{t}(j)\right)
$$

and hence:

$$
\begin{aligned}
\int \frac{N_{t}(j)^{1+\varphi}}{1+\varphi} d j= & \frac{N^{1+\varphi}}{1+\varphi} \\
& +N^{1+\varphi}\left[y_{h t}-a_{t}+\frac{1+\varphi}{2} y_{h t}^{2}-(1+\varphi) a_{t} y_{h t}\right. \\
& +\frac{1+\varphi}{2} a_{t}^{2}+\frac{1}{2} \varepsilon(1+\varphi \varepsilon) \operatorname{var}_{j}\left(\log p_{t}(j)\right)
\end{aligned}
$$


Finally, one uses the result in Woodford (2003, p. 400):

$$
E \sum_{t=0}^{\infty} \beta^{t} v a r_{j}\left(\log p_{t}(j)\right)=\frac{\theta}{(1-\theta)(1-\beta \theta)} E \sum_{t=0}^{\infty} \beta^{t} \pi_{h t}^{2}
$$

to get

$$
\begin{aligned}
E \sum_{t=0}^{\infty} \beta^{t} \int \frac{N_{t}(j)^{1+\varphi}}{1+\varphi} d j= & N^{1+\varphi} E \sum_{t=0}^{\infty} \beta^{t}\left[y_{h t}-a_{t}+\frac{1+\varphi}{2} y_{h t}^{2}-\right. \\
& \left.(1+\varphi) a_{t} y_{h t}+\frac{1+\varphi}{2} a_{t}^{2}+\Theta \pi_{h t}^{2}\right] \\
& +\frac{N^{1+\varphi}}{(1+\varphi)(1-\beta)}
\end{aligned}
$$

where

$$
\Theta=\frac{1}{2} \varepsilon(1+\varphi \varepsilon) \frac{\theta}{(1-\theta)(1-\beta \theta)}
$$

In sum, the relevant part of the utility function is:

$$
\begin{aligned}
U_{t}= & U+E \sum_{t=0}^{\infty} \beta^{t}\left\{\frac{C^{1-\sigma}}{\varsigma}\left(c_{t}+\frac{1-\sigma}{2} c_{t}^{2}\right)-N^{1+\varphi}\left[y_{h t}-a_{t}\right.\right. \\
& \left.\left.+\frac{1+\varphi}{2} y_{h t}^{2}-(1+\varphi) a_{t} y_{h t}+\frac{1+\varphi}{2} a_{t}^{2}+\Theta \pi_{h t}^{2}\right]\right\}
\end{aligned}
$$

where:

$$
U=\frac{1}{(1-\beta)}\left(\frac{C^{1-\sigma}}{\varsigma(1-\sigma)}-\frac{N^{1+\varphi}}{(1+\varphi)}\right)
$$

Now we have expressed the objective function without idiosyncratic variables, only in terms of aggregate ones. 


\section{References}

[1] Aoki, K. (2001) "Optimal Monetary Policy Response to Relative Price Changes" Journal of Monetary Economics 48, pp55-80.

[2] Benigno and Benigno, 2003, Price Stability in open economies, Review of Economic Studies 70, 743-764.

[3] Bergin, P., Shin, H., Tchakarov, I., 2007. Does exchange rate variability matter for welfare? A quantitative investigation of stabilization policies. European Economic Review 51(4), 1041-1058.

[4] Bodenstein, Martin, Christopher Erceg, and Luca Guerrieri, 2008, "Optimal Monetary Policy with Distinct Core and Headline Inflation Rates", Journal of Monetary Economics 55, pp.518-533.

[5] Corsetti and Pesenti, 2001 Welfare and Macroeconomic Independence, Quarterly Journal of Economics, 116, 421-445.

[6] Cova, P., Sondergaard, J., 2004. When should monetary policy target the exchange rate? Royal Economic Society Annual Conference, Paper Number 51.

[7] Deaton, Angus., 1998.Getting Prices Right: What Should be done?. Journal of Economics Perspectives-Vol 12, Num 1.

[8] Devereux and Engle, 2003, Monetary Policy in the open economy revisited: price setting and exchange rate flexibility, Review of Economic Studies 70, pp. $765-783$

[9] Devereux, M., P. Lane and J. Xu, 2006, Exchange Rates and Monetary Policy in Emerging Market Economies, Economic Journal.

[10] De Paoli, Bianca, 2009. Monetary policy and welfare in a small open economy. Journal of International Economics 77 (2009) 11-22.

[11] Galí, Jordi. 2008. Monetary Policy, Inflation, and the Business Cycle: An Introduction to the New Keynesian Framework

[12] Galí, Jordi and Tommaso Monacelli, 2005. Monetary Policy and Exchange Rate Volatility in a Small Open Economy. Review of Economic Studies (2005) $72,707-734$. 
[13] Goodfriend, M. and R. King, 2001, The Case for Price Stability, NBER Working paper 8423.

[14] Gouveia, Solange, 2007, Price Rigidity in Brazil: Evidence from CPI Micro Data, Working paper 143, Central Bank of Brazil.

[15] Jacks, David, Kevin O'Rourke, and Jeffrey Williamson, 2009, Commodity Price Volatility and World Market Integration since 1700, NBER working paper 14748

[16] Kilian, Lutz, 2009, "Not All Price Shocks are Alike: Disentangling Demand and Supply Shocks in the Crude Oil Market," American Economic Review, 99(3), pp.1053-69.

[17] Kollmann, R., (2002) "Monetary Policy Rules in the Open Economy: Effects on Welfare and Business Cycles" CEPR Discussion Papers 3279, C.E.P.R. Discussion Papers.

[18] Obstfeld and Rogoff, 2002, Global Implications of self-oriented national policy rules, Quarterly Journal of Economics, 117, pp. 503-535

[19] Rigobon, Robert, 2008. " "Distribution of Inflation Impact: The Recent Experience in Central America and Mexico" "

[20] Rose, Andrew, 2007, "A Stable International System Emerges: Inflation Targeting is Bretton Woods Reversed", Journal of International Money and Finance 26, pp. 663-81

[21] Schmitt-Grohe, S. and M. Martin Uribe, 2004. Solving dynamic general equilibrium models using a second-order approximation to the policy function. Journal of Economic Dynamics \& Control 28 (2004) 755 - 775

[22] Schmitt-Grohe, S. and M. Martin Uribe, 2007, "Optimal Simple and Implementable Monetary and Fiscal Rules", Journal of Monetary Economics, 54, 1702-1725.

[23] Sutherland, A, 2005, Incomplete Pass-through and welfare effects of exchange rate variability, Journal of International Economics, 65, pp.375-399.

[24] Woodford, Michael, Interest and Prices: Foundations of a Theory of Monetary Policy, Princeton University Press, 2003. 
Table 1: Correlations between World Inflation Indicators and Food and Oil Prices, 1990-2008 (all series HP detrended)

a) Contemporary Correlations

\begin{tabular}{r|rrrrr} 
& USWPI & World WPI & World CPI & Pfood & Poil \\
\hline USWPI & 1 & 0.83689 & 0.74349 & 0.61911 & 0.7255 \\
World WPI & 0.83689 & 1 & 0.66171 & 0.63273 & 0.46531 \\
World CPI & 0.74349 & 0.66171 & 1 & 0.5597 & 0.39451 \\
Pfood & 0.61911 & 0.63273 & 0.5597 & 1 & 0.17133 \\
Poil & 0.7255 & 0.46531 & 0.39451 & 0.17133 & 1
\end{tabular}

a) Lagged Correlations

\begin{tabular}{r|rrrrr} 
& USWPI & World WPI & World CPI & Pfood & Poil \\
\hline USWPI & 1 & 0.83689 & 0.74349 & 0.44189 & 0.29036 \\
World WPI & 0.83689 & 1 & 0.66171 & 0.46337 & 0.27692 \\
World CPI & 0.74349 & 0.66171 & 1 & 0.36737 & 0.52542 \\
Pfood $_{t \square 1}$ & 0.44189 & 0.46337 & 0.36737 & 1 & -0.03128 \\
Poil $_{t \square 1}$ & 0.29036 & 0.27692 & 0.52542 & -0.03128 & 1
\end{tabular}


Table 2: Causality Tests

47 observations used for estimation from 1962 to 2008

a) Food Prices -US WPI

Dependent variable is WPIGAP

Independent variables: ZGAP(-1) -ZGAP(-2)

Lagrange Multiplier Statistic $\operatorname{CHSQ}(2)=10.4873[.005]$

Likelihood Ratio Statistic $\operatorname{CHSQ}(2)=11.8668[.003]$

F Statistic $\mathrm{F}(2,42)=6.0317[.005]$

b) Oil Prices -US WPI

Dependent variable is WPIGAP

Independent variables: PROILGAP(-1) -PROILGAP(-2)

Lagrange Multiplier Statistic $\operatorname{CHSQ}(2)=1.4879[.475]$

Likelihood Ratio Statistic $\operatorname{CHSQ}(2)=1.5119[.470]$

F Statistic $\mathrm{F}(2,42)=.68653[.509]$

c) Oil -Food

Dependent variable is ZGAP

Independent variables: PROILGAP(-1) -PROILGAP(-2)

Lagrange Multiplier Statistic $\operatorname{CHSQ}(2)=1.1923[.551]$

Likelihood Ratio Statistic $\operatorname{CHSQ}(2)=1.2077[.547]$

F Statistic $\mathrm{F}(2,42)=.54659[.583]$

d) Food -Oil

Dependent variable is PROILGAP

Independent variables: Lagrange Multiplier Statistic ZGAP(-1) -ZGAP(-2)

Likelihood Ratio Statistic $\operatorname{CHSQ}(2)=14.1011[.001]$ $\operatorname{CHSQ}(2)=16.7653[.000]$

F Statistic $\mathrm{F}(2,42)=9.0010[.001]$ 
Table 3: Food Expenditure Shares

\begin{tabular}{|c|c|c|c|}
\hline Austria & $15.50 \%$ & Latvia & $40.40 \%$ \\
\hline Belgium & $16.10 \%$ & Lithuania & $45.45 \%$ \\
\hline Bulgaria & $43.36 \%$ & Luxemburg & $13.60 \%$ \\
\hline Costa Rica & $13.11 \%$ & Malta & $34.17 \%$ \\
\hline Cyprus & $26.40 \%$ & Mexico & $32.69 \%$ \\
\hline Czech Republic & $24.20 \%$ & Netherlands & $11.92 \%$ \\
\hline Denmark & $14.03 \%$ & Panama & $34.90 \%$ \\
\hline Estonia & $30.83 \%$ & Poland & $30.41 \%$ \\
\hline Finland & $15.63 \%$ & Portugal & $22.20 \%$ \\
\hline France & $15.08 \%$ & Romania & $58.74 \%$ \\
\hline Germany & $15.60 \%$ & Slovakia & $33.33 \%$ \\
\hline Greece & $21.28 \%$ & Slovenia & $22.91 \%$ \\
\hline Hungary & $29.40 \%$ & Spain & $25.40 \%$ \\
\hline Ireland & $17.98 \%$ & Sweden & $12.05 \%$ \\
\hline Italy & $28.26 \%$ & United Kingdom & $12.91 \%$ \\
\hline Overall Median & $23.55 \%$ & & \\
\hline Overall Mean & $25.26 \%$ & & \\
\hline EM Median & $32.69 \%$ & & \\
\hline EM Mean & $33.95 \%$ & & \\
\hline Advanced Median & $15.55 \%$ & & \\
\hline Advanced Mean & $16.81 \%$ & & \\
\hline
\end{tabular}


Table 4: Calibration of Linearized Model

\begin{tabular}{l|r|r|} 
Discount Factor & $\beta$ & 0.99 \\
Coefficient of risk aversion & $\sigma$ & {$[1,4]$} \\
Inverse of elasticity of labor supply & $\varphi$ & 1 \\
Degree of Openness & $\alpha$ & 0.4 \\
Average period between price adjustments & $\theta$ & 0.66 \\
Coefficient on domestic inflation in Taylor Rule & $\phi_{\pi}$ & 1.5 \\
Coefficient on output gap in Taylor Rule & $\phi_{y}$ & 0.125 \\
Parameter of persistence associated with moderately persistent monetary policy shock & $\rho_{v}$ & 0.6 \\
Parameter of persistence associated with moderately persistent world relative food price shock & $\rho_{z}$ & 0.85 \\
Price Elasticity of Foreign Demand for the home goods & {$[0.2,5]$} \\
Elasticity of substitution between varieties produced within country & $\epsilon$ \\
Elasticity of substitution between domestic and foreign goods & 6 \\
Ratio $C_{h} / Y_{h}$ in steady state & $\eta$ & {$[0.25,1]$} \\
\hline
\end{tabular}

Table 5: Calibration of the Model's Second-Order Representation and Policy Rules

\begin{tabular}{|c|c|c|}
\hline Discount Factor & $\beta$ & 0.99 \\
\hline Coefficient of risk aversion & $\sigma$ & {$[0.5,4]$} \\
\hline Inverse of elasticity of labor supply & $\varphi$ & {$[1,3]$} \\
\hline Degree of Openness & $\alpha$ & 0.4 \\
\hline Average period between price adjustments & $\theta$ & 0.66 \\
\hline Coefficient on domestic inflation in Taylor Rule & $\phi_{\pi}$ & {$[1,3]$} \\
\hline Coefficient on output gap in Taylor Rule & $\phi_{y}$ & 0 \\
\hline Parameter of persistence associated with persistent monetary policy shock & $\rho_{v}$ & {$[0.6,0.8]$} \\
\hline Parameter of persistence associated with persistent relative food's price shock & $\rho_{z}$ & {$[0.85,0.9]$} \\
\hline Elasticity of substitution between varieties produced within any given country & $\epsilon$ & 6 \\
\hline Elasticity of substitution between domestic and foreign goods & $\eta$ & {$[0.25,2]$} \\
\hline Ratio $C_{h} / Y_{h}$ en equilibrium & $\omega$ & {$[0.6,0.9]$} \\
\hline Index of foreign demand & $C^{*}$ & 1 \\
\hline Parameter associated with tastes and preferences & $\varsigma$ & {$[0.04,7]$} \\
\hline Constant on Perfect Risk Sharing Condition & $\varkappa$ & 1 \\
\hline Price Elasticity of Foreign Demand for the home goods & & {$[0.2,5]$} \\
\hline Standar Deviation associated with monetary policy shock & $\sigma_{v}$ & {$[0.0062,0.0167]$} \\
\hline Standar Deviation associated with relative food's price shock & $\sigma_{z}$ & {$[0.0001,0.05]$} \\
\hline Standar Deviation associated with productivity shock & $\sigma_{a}$ & 0.012 \\
\hline
\end{tabular}


Table 6: Welfare Comparisons with Baseline Calibration

$$
\phi_{\pi}=1.5, \rho_{\nu}=0.6, \sigma_{v}=0.6 \% \phi_{y}=0.0, \rho_{z}=0.85,
$$

$\rho_{a}=0.7, \sigma_{a}=1.2 \%, \phi=0.25, \gamma=1, \varphi=1, \sigma_{z}=5 \%, \omega=0.75$

\section{Domestic Inflation-CPI Inflation}

\begin{tabular}{|c|c|c|c|c|c|}
\hline$\sigma \backslash \eta$ & 0.25 & 0.5 & 0.75 & 1 & 2 \\
\hline 0.5 & -0.2165 & -0.2166 & -0.2146 & -0.2106 & -0.1801 \\
\hline 0.75 & -0.0222 & -0.0102 & 0.0052 & 0.0235 & 0.1153 \\
\hline 1 & 0.0068 & 0.0232 & 0.043 & 0.0656 & 0.1729 \\
\hline 2 & 0.061 & 0.0859 & 0.114 & 0.1443 & 0.2784 \\
\hline 4 & 0.0955 & 0.1256 & 0.1585 & 0.1934 & 0.3422 \\
\hline
\end{tabular}

\section{CPI Inflation -PEG}

\begin{tabular}{|c|c|c|c|c|c|}
\hline$\sigma \backslash \eta$ & 0.25 & 0.5 & 0.75 & 1 & 2 \\
\hline 0.5 & 0.2107 & 0.2218 & 0.2285 & 0.2315 & 0.2142 \\
\hline 0.75 & 0.025 & 0.0135 & -0.0021 & -0.0210 & -0.1184 \\
\hline 1 & -0.0069 & -0.0236 & -0.0442 & -0.0679 & -0.183 \\
\hline 2 & -0.0673 & -0.0937 & -0.1236 & -0.1565 & -0.3046 \\
\hline 4 & -0.1062 & -0.1386 & -0.1745 & -0.2130 & -0.3817 \\
\hline
\end{tabular}

Domestic Inflation-PEG

\begin{tabular}{|c|c|c|c|c|c|}
\hline$\sigma \backslash \eta$ & 0.25 & 0.5 & 0.75 & 1 & 2 \\
\hline 0.5 & -0.0057 & 0.0052 & 0.014 & 0.0209 & 0.0341 \\
\hline 0.75 & 0.0028 & 0.0033 & 0.0031 & 0.0025 & -0.0031 \\
\hline 1 & -0.0002 & -0.0004 & -0.0011 & -0.0023 & -0.01 \\
\hline 2 & -0.0063 & -0.0077 & -0.0097 & -0.0122 & -0.0262 \\
\hline 4 & -0.0107 & -0.013 & -0.016 & -0.0196 & -0.0395 \\
\hline
\end{tabular}

Dominance relative to SS

\begin{tabular}{|c|c|c|c|c|c|}
\hline$\sigma \backslash \eta$ & 0.25 & 0.5 & 0.75 & 1 & 2 \\
\hline 0.5 & 1 & 3 & 3 & 3 & 3 \\
\hline 0.75 & 3 & 3 & 2 & 2 & 2 \\
\hline 1 & 2 & 2 & 2 & 2 & 2 \\
\hline 2 & 2 & 2 & 2 & 2 & 2 \\
\hline 4 & 2 & 2 & 2 & 2 & 2 \\
\hline
\end{tabular}


Table 7: Welfare Comparisons with Low Variance of Food Prices

$$
\begin{gathered}
\phi_{\pi}=1.5, \rho_{\nu}=0.6, \sigma_{v}=0.6 \%, \rho_{a}=0.7, \sigma_{a}=1.2 \% \\
\phi_{y}=0.0, \rho_{z}=0.85, \phi=0.25, \gamma=1, \varphi=1, \sigma_{z}=0.01 \%, \omega=0.75
\end{gathered}
$$

Domestic Inflation-CPI Inflation

\begin{tabular}{|c|c|c|c|c|c|}
\hline$\sigma \backslash \eta$ & 0.25 & 0.5 & 0.75 & 1 & 2 \\
\hline 0.5 & -0.008 & -0.0076 & -0.0072 & -0.0067 & -0.0049 \\
\hline 0.75 & -0.0028 & -0.0027 & -0.0026 & -0.0024 & -0.0012 \\
\hline 1 & -0.0025 & -0.0025 & -0.0024 & -0.0023 & -0.0011 \\
\hline 2 & -0.0026 & -0.0027 & -0.0027 & -0.0026 & -0.0015 \\
\hline 4 & -0.003 & -0.0031 & -0.0032 & -0.0032 & -0.0021 \\
\hline
\end{tabular}

\section{CPI Inflation -PEG}

\begin{tabular}{|c|c|c|c|c|c|}
\hline$\sigma \backslash \eta$ & 0.25 & 0.5 & 0.75 & 1 & 2 \\
\hline 0.5 & 0.0507 & 0.0498 & 0.0489 & 0.0477 & 0.0426 \\
\hline 0.75 & 0.0093 & 0.008 & 0.0067 & 0.0052 & -0.0013 \\
\hline 1 & 0.0043 & 0.0029 & 0.0015 & 0 & -0.0068 \\
\hline 2 & -0.0035 & -0.005 & -0.0067 & -0.0083 & -0.0154 \\
\hline 4 & -0.0077 & -0.0094 & -0.0111 & -0.0127 & -0.02 \\
\hline
\end{tabular}

Domestic Inflation-PEG

\begin{tabular}{|c|c|c|c|c|c|}
\hline$\sigma \backslash \eta$ & 0.25 & 0.5 & 0.75 & 1 & 2 \\
\hline 0.5 & 0.0427 & 0.0422 & 0.0417 & 0.041 & 0.0377 \\
\hline 0.75 & 0.0065 & 0.0053 & 0.0041 & 0.0028 & -0.0025 \\
\hline 1 & 0.0018 & 0.0004 & -0.0009 & -0.0023 & -0.008 \\
\hline 2 & -0.0061 & -0.0077 & -0.0093 & -0.0109 & -0.017 \\
\hline 4 & -0.0107 & -0.0125 & -0.0142 & -0.0159 & -0.0221 \\
\hline
\end{tabular}

Dominance relative to SS

\begin{tabular}{|c|c|c|c|c|c|}
\hline$\sigma \backslash \eta$ & 0.25 & 0.5 & 0.75 & 1 & 2 \\
\hline 0.5 & 3 & 3 & 3 & 3 & 3 \\
\hline 0.75 & 3 & 3 & 3 & 3 & 1 \\
\hline 1 & 3 & 3 & 1 & 1 & 1 \\
\hline 2 & 1 & 1 & 1 & 1 & 1 \\
\hline 4 & 1 & 1 & 1 & 1 & 1 \\
\hline
\end{tabular}


Table 8: Model statistics Under Simulated Random Shocks SS with Balance Trade and $\omega=0.75$

\begin{tabular}{|c|c|c|c|c|c|c|c|c|}
\hline & \multicolumn{3}{|c|}{$\sigma=2 ; \eta=0.25 ; \gamma=1$} & \multicolumn{3}{|c|}{$\sigma=4 ; \eta=0.25 ; \gamma=1$} & & \\
\hline & PPI rule & CPI rule & PEG ule & PPI rule & CPI rule & PEG ule & & \\
\hline & Shocks to & Shocks to & Shocks to & Shocks to & Shocks to & Shocks to & & \\
\hline & $\mathrm{z}_{t}$ & $\mathrm{z}_{t}$ & $\mathrm{z}_{t}$ & $\mathrm{z}_{t}$ & $\mathrm{z}_{t}$ & $\mathrm{z}_{t}$ & & \\
\hline Standard deviations (in \%) & (1) & $(2)$ & $(3)$ & $(4)$ & $(5)$ & (6) & & \\
\hline Domestic Output & 0.367 & 1.137 & 0.863 & 0.000 & 0.936 & 0.945 & & \\
\hline Consumption & 1.154 & 1.152 & 0.546 & 0.606 & 0.584 & 0.292 & & \\
\hline CPI-based Real Exchange rate & 2.307 & 2.298 & 1.091 & 2.420 & 2.328 & 1.164 & & \\
\hline Home Good Price/CPI & 2.470 & 2.695 & 2.956 & 2.432 & 2.684 & 2.940 & & \\
\hline Domestic Inflation & 0.035 & 0.529 & 0.204 & 0.000 & 0.540 & 0.213 & & \\
\hline \multicolumn{9}{|l|}{ Means in \% of SS deviation } \\
\hline Domestic Output & -0.0044 & -0.2327 & -0.0445 & 0.000 & -0.194 & -0.033 & & \\
\hline Consumption & -0.0119 & -0.1699 & -0.0577 & -0.008 & -0.097 & -0.034 & & \\
\hline CPI-based Real Exchange rate & -0.0105 & -0.3263 & -0.1125 & -0.008 & -0.368 & -0.129 & & \\
\hline Home Good Price/CPI & 0.0709 & -0.0115 & 0.0954 & 0.067 & -0.027 & 0.088 & & \\
\hline Domestic Inflation & 0.0003 & -0.0135 & 0.0002 & 0.000 & -0.014 & 0.000 & & \\
\hline Natural Consumption & -0.013 & -0.0115 & -0.013 & -0.0076 & -0.0076 & -0.0076 & & \\
\hline Natural $\mathrm{X}_{t}$ & -0.0138 & -0.0089 & -0.0138 & -0.0083 & -0.0083 & -0.0083 & & \\
\hline \multirow[t]{5}{*}{ Consumption/Output ratio } & 99.99 & 100.06 & 99.99 & 99.99 & 100.10 & 100.00 & & \\
\hline & \multicolumn{3}{|c|}{$\sigma=4 ; \eta=0.25 ; \gamma=1$} & \multicolumn{2}{|c|}{$\sigma=4 ; \eta=0.25 ; \gamma=1$} & \multicolumn{3}{|c|}{$\sigma=4 ; \eta=0.25 ; \gamma=1$} \\
\hline & PPI rule & CPI rule & PEG rule & PPI rule & CPI rule & To all & To all & To all \\
\hline & Shocks to & Shocks to & Shocks to & Shocks to & Shocks to & Shocks & Shocks & Shocks \\
\hline & $\mathrm{a}_{t}$ & $\mathrm{a}_{t}$ & $\mathrm{a}_{t}$ & $\mathrm{v}_{t}$ & $\mathrm{v}_{t}$ & & & \\
\hline Standard deviations (in \%) & (7) & (8) & $(9)$ & $(10)$ & (11) & $(12)$ & (13) & (14) \\
\hline Domestic Output & 0.269 & 0.315 & 0.313 & 0.424 & 0.497 & 0.501 & 1.101 & 0.887 \\
\hline Consumption & 0.115 & 0.135 & 0.134 & 0.182 & 0.213 & 0.642 & 0.634 & 0.725 \\
\hline CPI-based Real Exchange rate & 0.461 & 0.539 & 0.537 & 0.726 & 0.851 & 2.562 & 2.525 & 2.898 \\
\hline Home Good Price/CPI & 0.154 & 0.180 & 0.179 & 0.242 & 0.284 & 2.448 & 2.704 & 2.471 \\
\hline Domestic Inflation & 0.224 & 0.192 & 0.142 & 0.088 & 0.132 & 0.241 & 0.593 & 0.398 \\
\hline \multicolumn{9}{|l|}{ Means in \% of SS deviation } \\
\hline Domestic Output & -0.048 & -0.039 & -0.031 & -0.013 & -0.022 & -0.061 & -0.254 & 0.005 \\
\hline Consumption & -0.021 & -0.017 & -0.013 & -0.006 & -0.010 & -0.035 & -0.124 & -0.008 \\
\hline CPI-based Real Exchange rate & -0.082 & -0.067 & -0.053 & -0.023 & -0.039 & -0.113 & -0.472 & 0.000 \\
\hline Home Good Price/CPI & -0.027 & -0.022 & -0.017 & -0.007 & -0.012 & 0.033 & -0.061 & 0.069 \\
\hline Domestic Inflation & 0.001 & 0.001 & 0.000 & -0.005 & -0.005 & -0.004 & -0.018 & 0.002 \\
\hline Natural Consumption & -0.004 & -0.004 & -0.004 & 0 & 0 & -0.0114 & -0.0114 & -0.0114 \\
\hline Natural $\mathrm{X}_{t}$ & -0.0038 & -0.0038 & -0.0038 & 0 & 0 & -0.0107 & -0.0107 & -0.0107 \\
\hline Consumption/Output ratio & 100.03 & 100.02 & 100.02 & 100.01 & 100.01 & 100.03 & 100.13 & 99.99 \\
\hline
\end{tabular}


Table 9: Welfare Comparisons with Higher Variance of Monetary Shocks

$$
\begin{gathered}
\phi_{\pi}=1.5, \rho_{\nu}=0.6, \sigma_{v}=1.25 \%, \rho_{a}=0.7, \sigma_{a}=1.2 \% \\
\phi_{y}=0.0, \rho_{z}=0.85, \phi=0.25, \gamma=1, \varphi=1, \sigma_{z}=5 \%, \omega=0.75
\end{gathered}
$$

Domestic Inflation-CPI Inflation

\begin{tabular}{|c|c|c|c|c|c|}
\hline$\sigma \backslash \eta$ & 0.25 & 0.5 & 0.75 & 1 & 2 \\
\hline 0.5 & -0.2437 & -0.2419 & -0.2378 & -0.2318 & -0.1932 \\
\hline 0.75 & -0.0259 & -0.012 & 0.0055 & 0.0259 & 0.1264 \\
\hline 1 & 0.0068 & 0.0252 & 0.047 & 0.0717 & 0.1878 \\
\hline 2 & 0.0663 & 0.0933 & 0.1234 & 0.1559 & 0.299 \\
\hline 4 & 0.1033 & 0.1355 & 0.1705 & 0.2076 & 0.3655 \\
\hline
\end{tabular}

\section{CPI Inflation -PEG}

\begin{tabular}{|c|c|c|c|c|c|}
\hline$\sigma \backslash \eta$ & 0.25 & 0.5 & 0.75 & 1 & 2 \\
\hline 0.5 & 0.3452 & 0.3532 & 0.3566 & 0.3558 & 0.3217 \\
\hline 0.75 & 0.0478 & 0.0329 & 0.0137 & -0.0092 & -0.1254 \\
\hline 1 & 0.0044 & -0.0157 & -0.04 & -0.0679 & -0.2021 \\
\hline 2 & -0.071 & -0.101 & -0.1349 & -0.1721 & -0.34 \\
\hline 4 & -0.1163 & -0.1524 & -0.1924 & -0.2353 & -0.4241 \\
\hline
\end{tabular}

Domestic Inflation-PEG

\begin{tabular}{|c|c|c|c|c|c|}
\hline$\sigma \backslash \eta$ & 0.25 & 0.5 & 0.75 & 1 & 2 \\
\hline 0.5 & 0.1015 & 0.1113 & 0.1188 & 0.1240 & 0.1285 \\
\hline 0.75 & 0.0219 & 0.021 & 0.0192 & 0.0166 & 0.001 \\
\hline 1 & 0.0112 & 0.0095 & 0.007 & 0.0038 & -0.0143 \\
\hline 2 & -0.0047 & -0.0077 & -0.0115 & -0.0162 & -0.041 \\
\hline 4 & -0.0129 & -0.0169 & -0.0219 & -0.0277 & -0.0585 \\
\hline
\end{tabular}

Dominance relative to SS

\begin{tabular}{|c|c|c|c|c|c|}
\hline$\sigma \backslash \eta$ & 0.25 & 0.5 & 0.75 & 1 & 2 \\
\hline 0.5 & 3 & 3 & 3 & 3 & 3 \\
\hline 0.75 & 3 & 3 & 3 & 2 & 2 \\
\hline 1 & 3 & 2 & 2 & 2 & 2 \\
\hline 2 & 2 & 2 & 2 & 2 & 2 \\
\hline 4 & 2 & 2 & 2 & 2 & 2 \\
\hline
\end{tabular}


Table 10: Welfare Comparisons with Lower Variance of Productivity Shocks

$$
\begin{gathered}
\phi_{\pi}=1.5, \rho_{\nu}=0.6, \sigma_{v}=0.6 \%, \rho_{a}=0.7, \sigma_{a}=0.7 \% \\
\phi_{y}=0.0, \rho_{z}=0.85, \phi=0.25, \gamma=1, \varphi=1, \sigma_{z}=5 \%, \omega=0.75
\end{gathered}
$$

\section{Domestic Inflation-CPI Inflation}

\begin{tabular}{|c|c|c|c|c|c|}
\hline$\sigma \backslash \eta$ & 0.25 & 0.5 & 0.75 & 1 & 2 \\
\hline 0.5 & -0.2178 & -0.2177 & -0.2155 & -0.2113 & -0.1801 \\
\hline 0.75 & -0.0213 & -0.0089 & 0.007 & 0.0256 & 0.1188 \\
\hline 1 & 0.0084 & 0.0253 & 0.0456 & 0.0685 & 0.1773 \\
\hline 2 & 0.064 & 0.0895 & 0.118 & 0.1488 & 0.2845 \\
\hline 4 & 0.0994 & 0.1301 & 0.1635 & 0.1989 & 0.3493 \\
\hline
\end{tabular}

\section{CPI Inflation -PEG}

\begin{tabular}{|c|c|c|c|c|c|}
\hline$\sigma \backslash \eta$ & 0.25 & 0.5 & 0.75 & 1 & 2 \\
\hline 0.5 & 0.171 & 0.183 & 0.1908 & 0.1971 & 0.1825 \\
\hline 0.75 & 0.0198 & 0.01 & -0.0038 & -0.0211 & -0.1114 \\
\hline 1 & -0.0074 & -0.0222 & -0.0409 & -0.0632 & -0.1705 \\
\hline 2 & -0.0598 & -0.0841 & -0.1121 & -0.1437 & -0.2832 \\
\hline 4 & -0.0942 & -0.1244 & -0.1582 & -0.1956 & -0.3553 \\
\hline
\end{tabular}

Domestic Inflation-PEG

\begin{tabular}{|c|c|c|c|c|c|}
\hline$\sigma \backslash \eta$ & 0.25 & 0.5 & 0.75 & 1 & 2 \\
\hline 0.5 & -0.0468 & -0.0347 & -0.0246 & -0.0142 & 0.0024 \\
\hline 0.75 & -0.0015 & 0.0011 & 0.0031 & 0.0046 & 0.0074 \\
\hline 1 & 0.001 & 0.0031 & 0.0047 & 0.0054 & 0.0068 \\
\hline 2 & 0.0042 & 0.0054 & 0.0059 & 0.0052 & 0.0012 \\
\hline 4 & 0.0052 & 0.0057 & 0.0053 & 0.0033 & -0.006 \\
\hline
\end{tabular}

Dominance relative to SS

\begin{tabular}{|c|c|c|c|c|c|}
\hline$\sigma \backslash \eta$ & 0.25 & 0.5 & 0.75 & 1 & 2 \\
\hline 0.5 & 1 & 1 & 1 & 1 & 3 \\
\hline 0.75 & 1 & 3 & 2 & 2 & 2 \\
\hline 1 & 2 & 2 & 2 & 2 & 2 \\
\hline 2 & 2 & 2 & 2 & 2 & 2 \\
\hline
\end{tabular}


Table 11: Welfare Comparisons with "Hawkish" Taylor Rule

$$
\phi_{\pi}=3, \rho_{\nu}=0.6, \sigma_{v}=0.6 \%, \rho_{a}=0.7, \sigma_{a}=1.2 \%
$$

$\phi_{y}=0.0, \rho_{z}=0.85, \phi=0.25, \gamma=1, \varphi=1, \sigma_{z}=5 \%, \omega=0.75$

Domestic Inflation-CPI Inflation

\begin{tabular}{|c|c|c|c|c|c|}
\hline$\sigma \backslash \eta$ & 0.25 & 0.5 & 0.75 & 1 & 2 \\
\hline 0.5 & -0.5573 & -0.5171 & -0.4812 & -0.4495 & -0.3568 \\
\hline 0.75 & -0.0923 & -0.0777 & -0.0653 & -0.0549 & -0.0287 \\
\hline 1 & -0.0531 & -0.0406 & -0.03 & -0.0211 & 0.0015 \\
\hline 2 & -0.0013 & 0.009 & 0.0179 & 0.0255 & 0.0459 \\
\hline 4 & 0.0225 & 0.0323 & 0.0408 & 0.0482 & 0.0687 \\
\hline
\end{tabular}

CPI Inflation -PEG

\begin{tabular}{|c|c|c|c|c|c|}
\hline$\sigma \backslash \eta$ & 0.25 & 0.5 & 0.75 & 1 & 2 \\
\hline 0.5 & 0.4458 & 0.4329 & 0.4193 & 0.4076 & 0.3522 \\
\hline 0.75 & 0.0938 & 0.0851 & 0.0768 & 0.0694 & 0.0543 \\
\hline 1 & 0.0607 & 0.0525 & 0.045 & 0.0384 & 0.0299 \\
\hline 2 & 0.0149 & 0.0074 & 0.0012 & -0.0042 & -0.0018 \\
\hline 4 & -0.0072 & -0.0143 & -0.0199 & -0.0246 & -0.0165 \\
\hline
\end{tabular}

Domestic Inflation-PEG

\begin{tabular}{|c|c|c|c|c|c|}
\hline$\sigma \backslash \eta$ & 0.25 & 0.5 & 0.75 & 1 & 2 \\
\hline 0.5 & -0.1116 & -0.0841 & -0.0619 & -0.0418 & -0.0046 \\
\hline 0.75 & 0.0015 & 0.0074 & 0.0115 & 0.0145 & 0.0256 \\
\hline 1 & 0.0076 & 0.0119 & 0.015 & 0.0172 & 0.0315 \\
\hline 2 & 0.0136 & 0.0164 & 0.0191 & 0.0213 & 0.044 \\
\hline 4 & 0.0153 & 0.0179 & 0.0209 & 0.0235 & 0.0522 \\
\hline
\end{tabular}

Dominance relative to SS

\begin{tabular}{|c|c|c|c|c|c|}
\hline$\sigma \backslash \eta$ & 0.25 & 0.5 & 1 & 0.75 & 2 \\
\hline 0.5 & 1 & 1 & 1 & 1 & 1 \\
\hline 0.75 & 3 & 3 & 3 & 3 & 3 \\
\hline 1 & 3 & 3 & 3 & 3 & 3 \\
\hline 2 & 3 & 3 & 3 & 2 & 3 \\
\hline 4 & 2 & 2 & 2 & 2 & 2 \\
\hline
\end{tabular}


Table 12: Welfare Comparisons with Taylor Rule with Moderate Reaction to Output Gap

$$
\begin{gathered}
\phi_{\pi}=1.5, \rho_{\nu}=0.6, \sigma_{v}=0.6 \%, \rho_{a}=0.7, \sigma_{a}=1.2 \% \\
\phi_{y}=0.125, \rho_{z}=0.85, \phi=0.25, \gamma=1, \varphi=1, \sigma_{z}=5 \%, \omega=0.75
\end{gathered}
$$

Domestic Inflation-CPI Inflation

\begin{tabular}{|c|c|c|c|c|c|}
\hline$\sigma \backslash \eta$ & 0.25 & 0.5 & 0.75 & 1 & 2 \\
\hline 0.5 & -0.1187 & -0.1146 & -0.1102 & -0.1226 & -0.0867 \\
\hline 0.75 & -0.0197 & -0.0139 & -0.0068 & 0.0046 & 0.0384 \\
\hline 1 & -0.0035 & 0.0045 & 0.0137 & 0.0238 & 0.0679 \\
\hline 2 & 0.0311 & 0.0439 & 0.0577 & 0.0564 & 0.1288 \\
\hline 4 & 0.0574 & 0.0736 & 0.0904 & 0.0749 & 0.171 \\
\hline
\end{tabular}

CPI Inflation -PEG

\begin{tabular}{|c|c|c|c|c|c|}
\hline$\sigma \backslash \eta$ & 0.25 & 0.5 & 0.75 & 1 & 2 \\
\hline 0.5 & 0.0193 & 0.038 & 0.0523 & 0.0776 & 0.0789 \\
\hline 0.75 & 0.0194 & 0.0181 & 0.0144 & 0.0058 & -0.0189 \\
\hline 1 & 0.0074 & 0.0028 & -0.0038 & -0.0121 & -0.0457 \\
\hline 2 & -0.0244 & -0.0351 & -0.0471 & -0.0435 & -0.1046 \\
\hline 4 & -0.0515 & -0.0661 & -0.0815 & -0.0615 & -0.1487 \\
\hline
\end{tabular}

Domestic Inflation-PEG

\begin{tabular}{|c|c|c|c|c|c|}
\hline$\sigma \backslash \eta$ & 0.25 & 0.5 & 0.75 & 1 & 2 \\
\hline 0.5 & -0.0994 & -0.0766 & -0.0579 & -0.0450 & -0.0078 \\
\hline 0.75 & -0.0003 & 0.0042 & 0.0076 & 0.0104 & 0.0195 \\
\hline 1 & 0.0039 & 0.0073 & 0.0099 & 0.012 & 0.0222 \\
\hline 2 & 0.0067 & 0.0088 & 0.0106 & 0.0129 & 0.0242 \\
\hline 4 & 0.006 & 0.0075 & 0.009 & 0.0134 & 0.0223 \\
\hline
\end{tabular}

Dominance relative to SS

\begin{tabular}{|c|c|c|c|c|c|}
\hline$\sigma \backslash \eta$ & 0.25 & 0.5 & 0.75 & 1 & 2 \\
\hline 0.5 & 1 & 1 & 1 & 1 & 1 \\
\hline 0.75 & 1 & 3 & 3 & 3 & 2 \\
\hline 1 & 3 & 3 & 2 & 2 & 2 \\
\hline 2 & 2 & 2 & 2 & 2 & 2 \\
\hline 4 & 2 & 2 & 2 & 2 & 2 \\
\hline
\end{tabular}


Table 13: Welfare Comparisons with High Export Price Elasticity

$$
\phi_{\pi}=1.5, \rho_{\nu}=0.6, \sigma_{v}=0.6 \%, \rho_{a}=0.857, \sigma_{a}=1.2 \%
$$

$$
\phi_{y}=0.0, \rho_{z}=0.85, \phi=0.25, \gamma=5, \varphi=1, \sigma_{z}=5 \%, \omega=0.75
$$

Domestic Inflation-CPI Inflation

\begin{tabular}{|c|c|c|c|c|c|}
\hline$\sigma \backslash \eta$ & 0.25 & 0.5 & 0.75 & 1 & 2 \\
\hline 0.5 & -0.1321 & -0.1165 & -0.1008 & -0.0849 & -0.0211 \\
\hline 0.75 & 0.169 & 0.1975 & 0.226 & 0.2542 & 0.3638 \\
\hline 1 & 0.2255 & 0.2569 & 0.2881 & 0.3189 & 0.4371 \\
\hline 2 & 0.3273 & 0.3635 & 0.3991 & 0.4340 & 0.5655 \\
\hline 4 & 0.388 & 0.4267 & 0.4646 & 0.5016 & 0.6397 \\
\hline
\end{tabular}

CPI Inflation -PEG

\begin{tabular}{|c|c|c|c|c|c|}
\hline$\sigma \backslash \eta$ & 0.25 & 0.5 & 0.75 & 1 & 2 \\
\hline 0.5 & 0.0912 & 0.0854 & 0.0784 & 0.0990 & 0.0323 \\
\hline 0.75 & -0.0767 & -0.0979 & -0.1193 & -0.2390 & -0.2239 \\
\hline 1 & -0.1162 & -0.1403 & -0.1644 & -0.3041 & -0.2805 \\
\hline 2 & -0.1916 & -0.2208 & -0.2497 & -0.4216 & -0.3864 \\
\hline 4 & -0.2389 & -0.271 & -0.3028 & -0.4921 & -0.4517 \\
\hline
\end{tabular}

Domestic Inflation-PEG

\begin{tabular}{|c|c|c|c|c|c|}
\hline$\sigma \backslash \eta$ & 0.25 & 0.5 & 0.75 & 1 & 2 \\
\hline 0.5 & 0.0014 & 0.0065 & 0.0105 & 0.0141 & 0.0189 \\
\hline 0.75 & 0.014 & 0.0153 & 0.0163 & 0.0152 & 0.0188 \\
\hline 1 & 0.0144 & 0.0156 & 0.0164 & 0.0148 & 0.0179 \\
\hline 2 & 0.0143 & 0.0149 & 0.0151 & 0.0124 & 0.0129 \\
\hline 4 & 0.0134 & 0.0135 & 0.0131 & 0.0095 & 0.0071 \\
\hline
\end{tabular}

Dominance relative to SS

\begin{tabular}{|c|c|c|c|c|c|}
\hline$\sigma \backslash \eta$ & 0.25 & 0.5 & 0.75 & 1 & 2 \\
\hline 0.5 & 3 & 3 & 3 & 3 & 3 \\
\hline 0.75 & 2 & 2 & 2 & 2 & 2 \\
\hline 1 & 2 & 2 & 2 & 2 & 2 \\
\hline 2 & 2 & 2 & 2 & 2 & 2 \\
\hline 4 & 2 & 2 & 2 & 2 & 2 \\
\hline
\end{tabular}


Table 14: Welfare Comparisons with Lower Elasticity of Labor Supply

$$
\begin{gathered}
\phi_{\pi}=1.5, \rho_{\nu}=0.6, \sigma_{v}=0.6 \%, \rho_{a}=0.7, \sigma_{a}=1.2 \% \\
\phi_{y}=0.0, \rho_{z}=0.85, \phi=0.25, \gamma=1, \varphi=3, \sigma_{z}=5 \%, \omega=0.75
\end{gathered}
$$

Domestic Inflation-CPI Inflation

\begin{tabular}{|c|c|c|c|c|c|}
\hline$\sigma \backslash \eta$ & 0.25 & 0.5 & 0.75 & 1 & 2 \\
\hline 0.5 & -0.505 & -0.5177 & -0.5236 & -0.5236 & -0.4773 \\
\hline 0.75 & -0.0589 & -0.0355 & -0.0012 & 0.0418 & 0.2673 \\
\hline 1 & 0.0033 & 0.0418 & 0.0909 & 0.1481 & 0.4226 \\
\hline 2 & 0.1305 & 0.2005 & 0.2794 & 0.3642 & 0.7263 \\
\hline 4 & 0.221 & 0.3119 & 0.4096 & 0.5114 & 0.9226 \\
\hline
\end{tabular}

CPI Inflation -PEG

\begin{tabular}{|c|c|c|c|c|c|}
\hline$\sigma \backslash \eta$ & 0.25 & 0.5 & 0.75 & 1 & 2 \\
\hline 0.5 & 0.3557 & 0.3957 & 0.4259 & 0.4528 & 0.462 \\
\hline 0.75 & 0.0487 & 0.0321 & 0.0037 & -0.0345 & -0.2577 \\
\hline 1 & -0.0078 & -0.0404 & -0.0849 & -0.1401 & -0.4246 \\
\hline 2 & -0.1295 & -0.1966 & -0.2756 & -0.3661 & -0.7777 \\
\hline 4 & -0.2211 & -0.3131 & -0.4169 & -0.5320 & -1.0311 \\
\hline
\end{tabular}

Domestic Inflation-PEG

\begin{tabular}{|c|c|c|c|c|c|}
\hline$\sigma \backslash \eta$ & 0.25 & 0.5 & 0.75 & 1 & 2 \\
\hline 0.5 & -0.1494 & -0.122 & -0.0977 & -0.0708 & -0.0153 \\
\hline 0.75 & -0.0102 & -0.0034 & 0.0025 & 0.0072 & 0.0096 \\
\hline 1 & -0.0044 & 0.0014 & 0.006 & 0.0080 & -0.002 \\
\hline 2 & 0.001 & 0.0039 & 0.0037 & -0.0018 & -0.0513 \\
\hline 4 & -0.0002 & -0.0013 & -0.0072 & -0.0261 & -0.1084 \\
\hline
\end{tabular}

Dominance relative to SS

\begin{tabular}{|c|c|c|c|c|c|}
\hline$\sigma \backslash \eta$ & 0.25 & 0.5 & 0.75 & 1 & 2 \\
\hline 0.5 & 1 & 1 & 1 & 1 & 1 \\
\hline 0.75 & 1 & 1 & 3 & 2 & 2 \\
\hline 1 & 2 & 2 & 2 & 2 & 2 \\
\hline 2 & 2 & 2 & 2 & 2 & 2 \\
\hline 4 & 2 & 2 & 2 & 2 & 2 \\
\hline
\end{tabular}


Table 15: Welfare Comparisons with World Inflation Variability

$$
\begin{gathered}
\phi_{\pi}=1.5, \rho_{\nu}=0.6, \sigma_{v}=0.6 \%, \rho_{a}=0.7, \sigma_{a}=1.2 \% \\
\phi_{y}=0.0, \rho_{z}=0.85, \phi=0.25, \gamma=1, \varphi=1, \sigma_{z}=5 \%, \omega=0.75 \\
\sigma_{p}=1.3 \%, \rho_{p}=0.99
\end{gathered}
$$

Domestic Inflation-CPI Inflation

\begin{tabular}{|c|c|c|c|c|c|}
\hline$\sigma \backslash \eta$ & 0.25 & 0.5 & 0.75 & 1 & 2 \\
\hline 0.5 & -0.2165 & -0.2166 & -0.2146 & -0.2106 & -0.1801 \\
\hline 0.75 & -0.0222 & -0.0102 & 0.0052 & 0.0235 & 0.1153 \\
\hline 1 & 0.0068 & 0.0232 & 0.043 & 0.0656 & 0.1729 \\
\hline 2 & 0.061 & 0.0859 & 0.114 & 0.1443 & 0.2784 \\
\hline 4 & 0.0955 & 0.1256 & 0.1585 & 0.1943 & 0.3422 \\
\hline
\end{tabular}

\section{CPI Inflation -PEG}

\begin{tabular}{|c|c|c|c|c|c|}
\hline$\sigma \backslash \eta$ & 0.25 & 0.5 & 0.75 & 1 & 2 \\
\hline 0.5 & 0.0407 & 0.057 & 0.0691 & 0.0776 & 0.0846 \\
\hline 0.75 & 0.005 & 0.0008 & -0.0072 & -0.0185 & -0.084 \\
\hline 1 & -0.0083 & -0.0173 & -0.03 & -0.0457 & -0.1277 \\
\hline 2 & -0.0405 & -0.0585 & -0.08 & -0.1043 & -0.2176 \\
\hline 4 & -0.065 & -0.0887 & -0.1158 & -0.1455 & -0.2784 \\
\hline
\end{tabular}

Domestic Inflation-PEG

\begin{tabular}{|c|c|c|c|c|c|}
\hline$\sigma \backslash \eta$ & 0.25 & 0.5 & 0.75 & 1 & 2 \\
\hline 0.5 & -0.1757 & -0.1596 & -0.1455 & -0.1330 & -0.0955 \\
\hline 0.75 & -0.0172 & -0.0094 & -0.0021 & 0.0050 & 0.0314 \\
\hline 1 & -0.0016 & 0.0059 & 0.013 & 0.0198 & 0.0452 \\
\hline 2 & 0.0205 & 0.0274 & 0.0339 & 0.0400 & 0.0609 \\
\hline 4 & 0.0305 & 0.0369 & 0.0427 & 0.0479 & 0.0638 \\
\hline
\end{tabular}

Dominance relative to SS

\begin{tabular}{|c|c|c|c|c|c|}
\hline$\sigma \backslash \eta$ & 0.25 & 0.5 & 0.75 & 1 & 2 \\
\hline 0.5 & 1 & 1 & 1 & 1 & 1 \\
\hline 0.75 & 1 & 1 & 2 & 2 & 2 \\
\hline 1 & 2 & 2 & 2 & 2 & 2 \\
\hline 2 & 2 & 2 & 2 & 2 & 2 \\
\hline 4 & 2 & 2 & 2 & 2 & 2 \\
\hline
\end{tabular}


Table 16: Welfare Comparisons with Higher Food Import Share

$$
\begin{gathered}
\phi_{\pi}=1.5, \rho_{\nu}=0.6, \sigma_{v}=0.6 \%, \rho_{a}=0.85, \sigma_{a}=1.2 \% \\
\phi_{y}=0.0, \rho_{z}=0.85, \phi=0.25, \gamma=1, \varphi=1, \sigma_{z}=5 \%, \omega=0.6 \\
\sigma_{p}=1.3 \%, \rho_{p}=0.99
\end{gathered}
$$

Domestic Inflation-CPI Inflation

\begin{tabular}{|c|c|c|c|c|c|}
\hline$\sigma \backslash \eta$ & 0.25 & 0.5 & 0.75 & 1 & 2 \\
\hline 0.5 & -0.491 & -0.4813 & -0.4647 & -0.4372 & -0.3137 \\
\hline 0.75 & 0.0389 & 0.0959 & 0.1568 & 0.2080 & 0.4834 \\
\hline 1 & 0.1428 & 0.2087 & 0.2775 & 0.3297 & 0.6297 \\
\hline 2 & 0.3333 & 0.4129 & 0.4934 & 0.5440 & 0.8806 \\
\hline 4 & 0.4481 & 0.5344 & 0.6206 & 0.6681 & 1.0222 \\
\hline
\end{tabular}

\section{CPI Inflation -PEG}

\begin{tabular}{|c|c|c|c|c|c|}
\hline$\sigma \backslash \eta$ & 0.25 & 0.5 & 0.75 & 1 & 2 \\
\hline 0.5 & 0.3451 & 0.3514 & 0.3492 & 0.3401 & 0.2543 \\
\hline 0.75 & -0.0319 & -0.0775 & -0.1275 & -0.1807 & -0.4074 \\
\hline 1 & -0.1176 & -0.1720 & -0.2301 & -0.2906 & -0.5399 \\
\hline 2 & -0.2808 & -0.3498 & -0.4211 & -0.4934 & -0.7789 \\
\hline 4 & -0.3830 & -0.4600 & -0.5383 & -0.6170 & -0.9216 \\
\hline
\end{tabular}

Domestic Inflation-PEG

\begin{tabular}{|c|c|c|c|c|c|}
\hline$\sigma \backslash \eta$ & 0.25 & 0.5 & 0.75 & 1 & 2 \\
\hline 0.5 & -0.1376 & -0.1228 & -0.1094 & -0.0971 & -0.0569 \\
\hline 0.75 & -0.0006 & 0.0089 & 0.0182 & 0.0273 & 0.0604 \\
\hline 1 & 0.0119 & 0.0214 & 0.0305 & 0.0392 & 0.0690 \\
\hline 2 & 0.0269 & 0.0356 & 0.0436 & 0.0507 & 0.0705 \\
\hline 4 & 0.0312 & 0.0389 & 0.0456 & 0.0512 & 0.0628 \\
\hline
\end{tabular}

Dominance relative to SS

\begin{tabular}{|c|c|c|c|c|c|}
\hline$\sigma \backslash \eta$ & 0.25 & 0.5 & 0.75 & 1 & 2 \\
\hline 0.5 & 1 & 1 & 1 & 1 & 1 \\
\hline 0.75 & 2 & 2 & 2 & 2 & 2 \\
\hline 1 & 2 & 2 & 2 & 2 & 2 \\
\hline 2 & 2 & 2 & 2 & 2 & 2 \\
\hline 4 & 2 & 2 & 2 & 2 & 2 \\
\hline
\end{tabular}


Figure 1: World WPI and World Relative Food Prices

(in deviations from HP-trend)

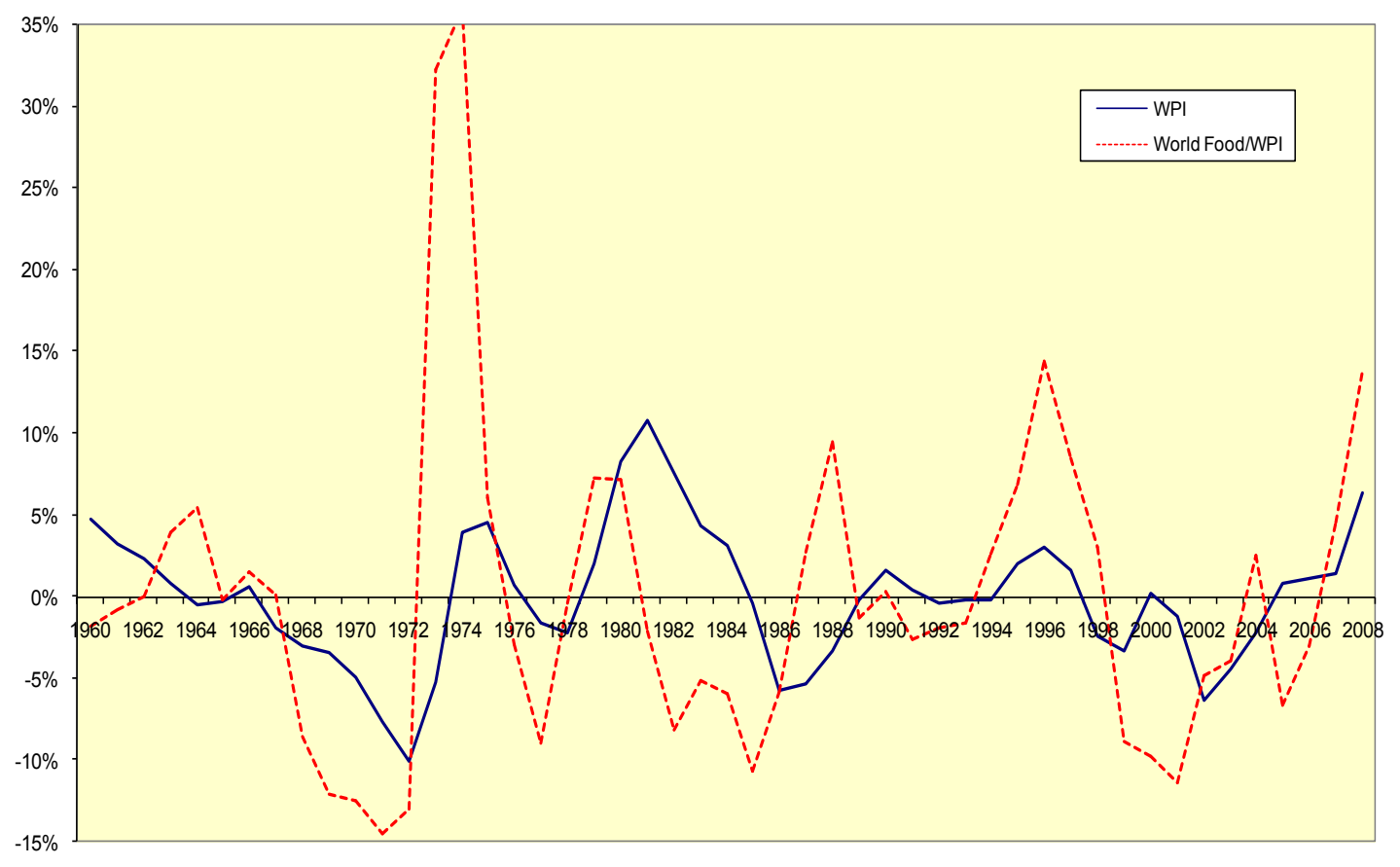




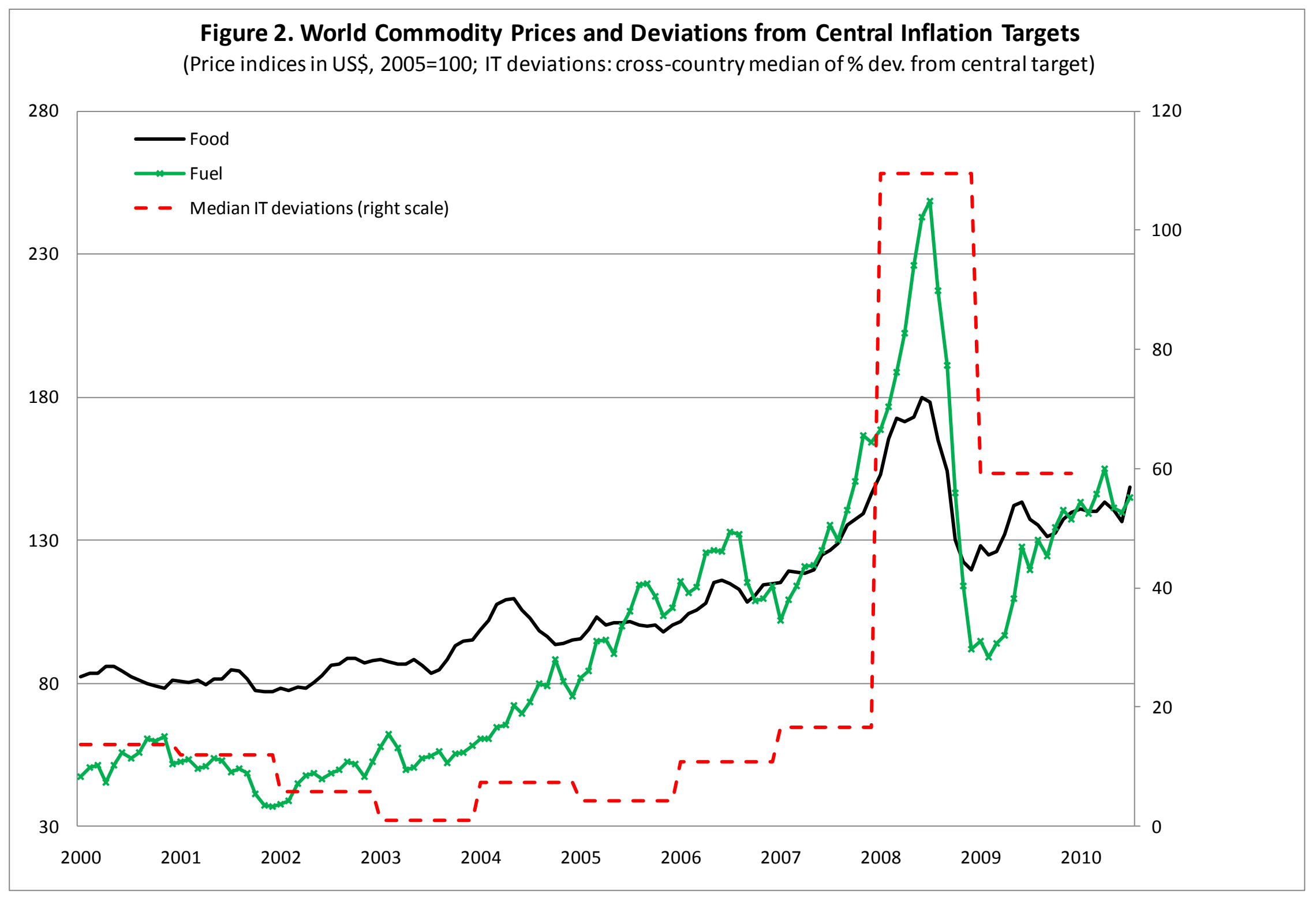


Figure 3: Effects of Food Price Shocks on Natural Output and the Terms of Trade

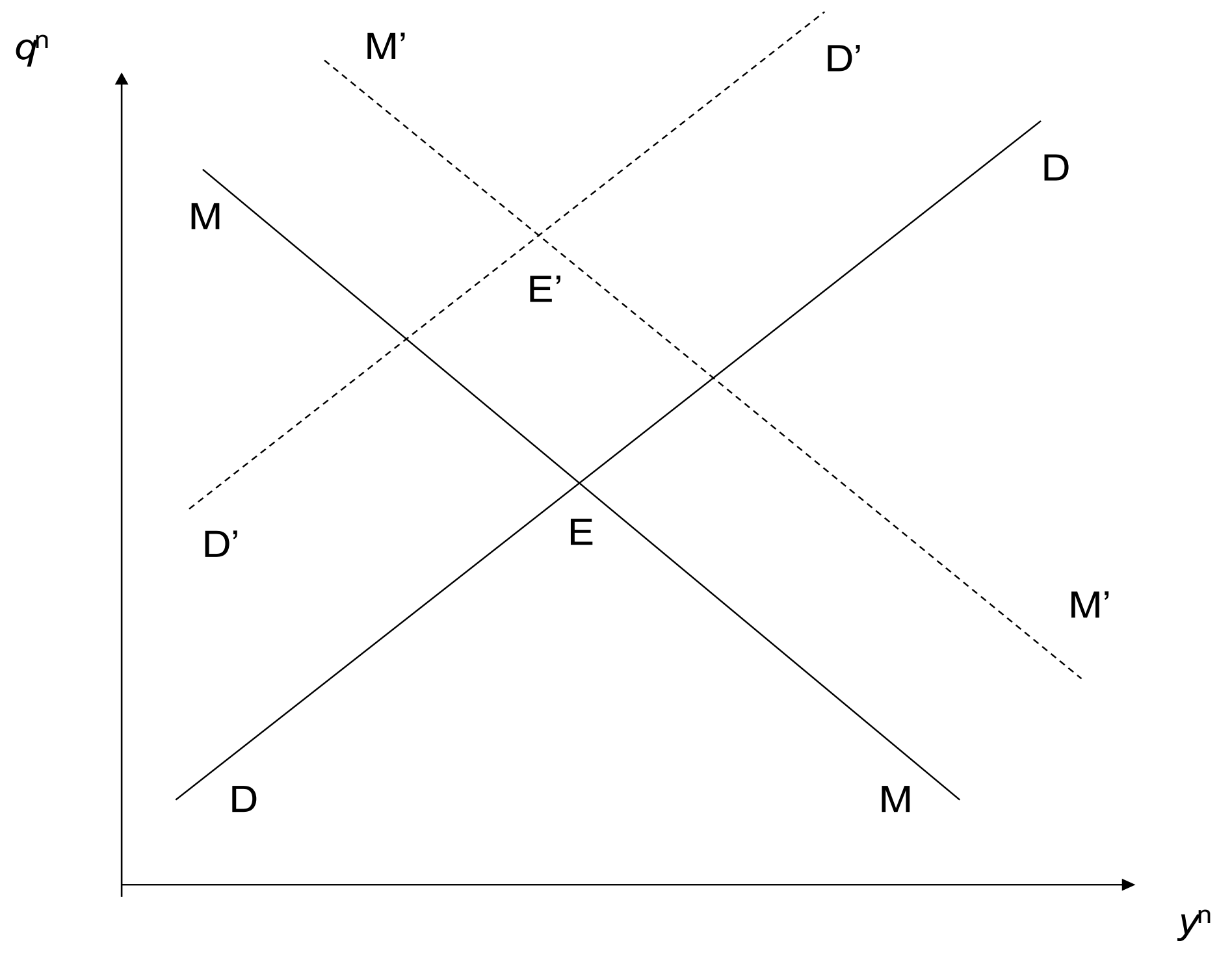


Figure 4: Impulse Responses of a $100 \%$ increase in world food prices with sigma $=2$ and eta $=[0.25,0.5,0.5,2]$ and gamma $=1$ with PPI
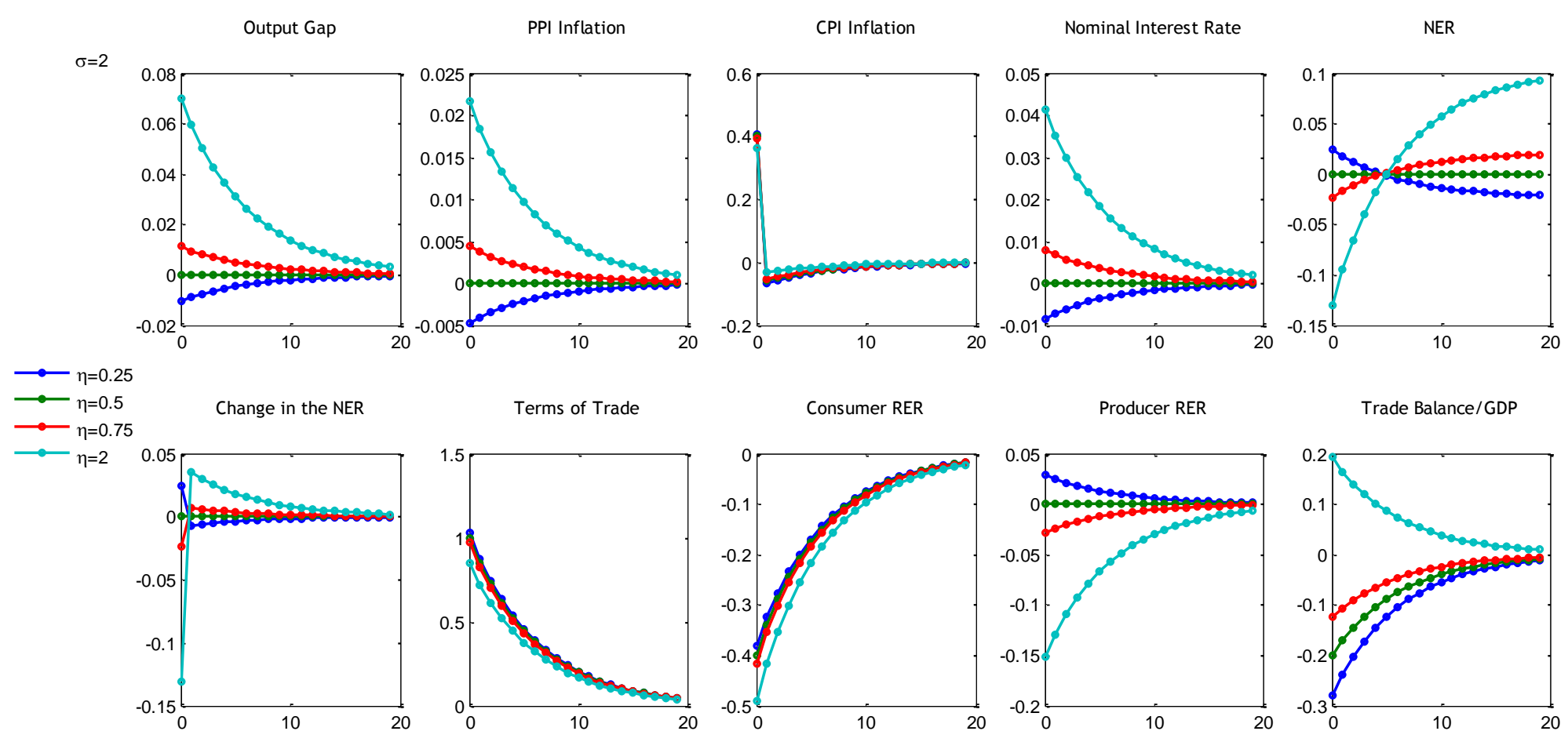

Real Wage

Employment

Natural Output

Consumption

Change in the Mark-up
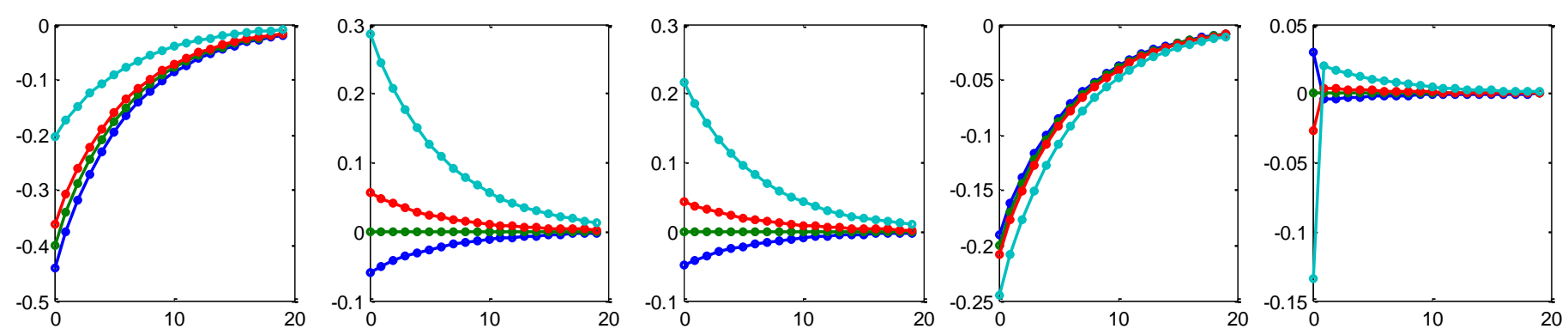
Figure 5: Impulse Responses of a $100 \%$ increase in world food prices with sigma $=2$ and eta $=[0.25,0.5,0.5,2]$ and gamma 1 with $\mathrm{CPI}$ rule
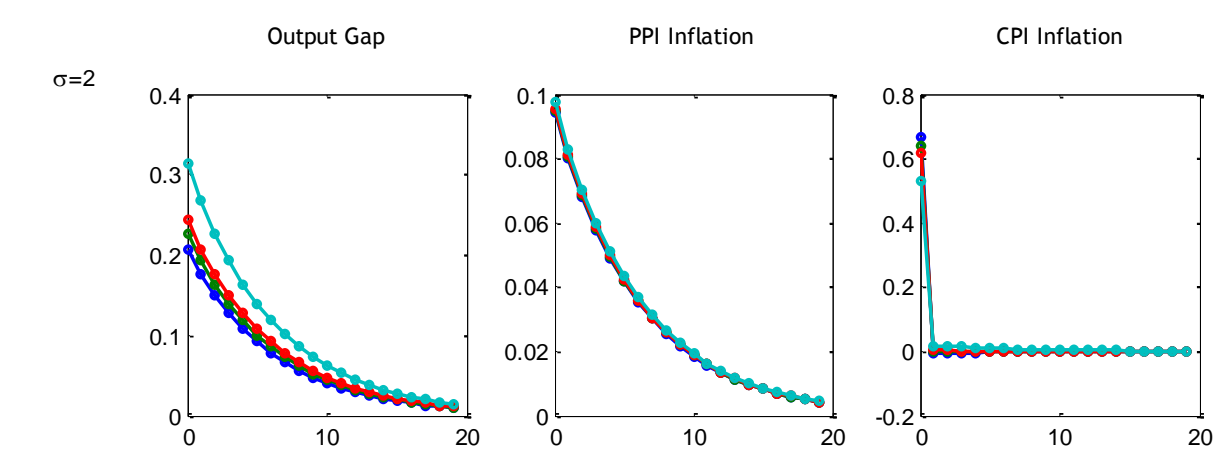

Nominal Interest Rate
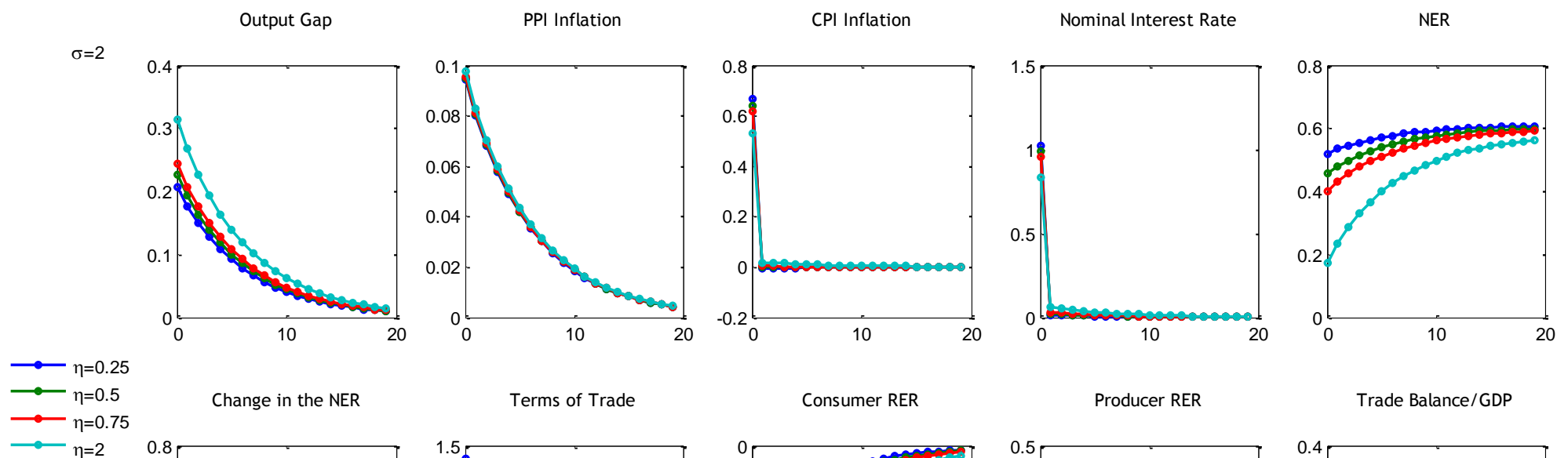

Change in the NER
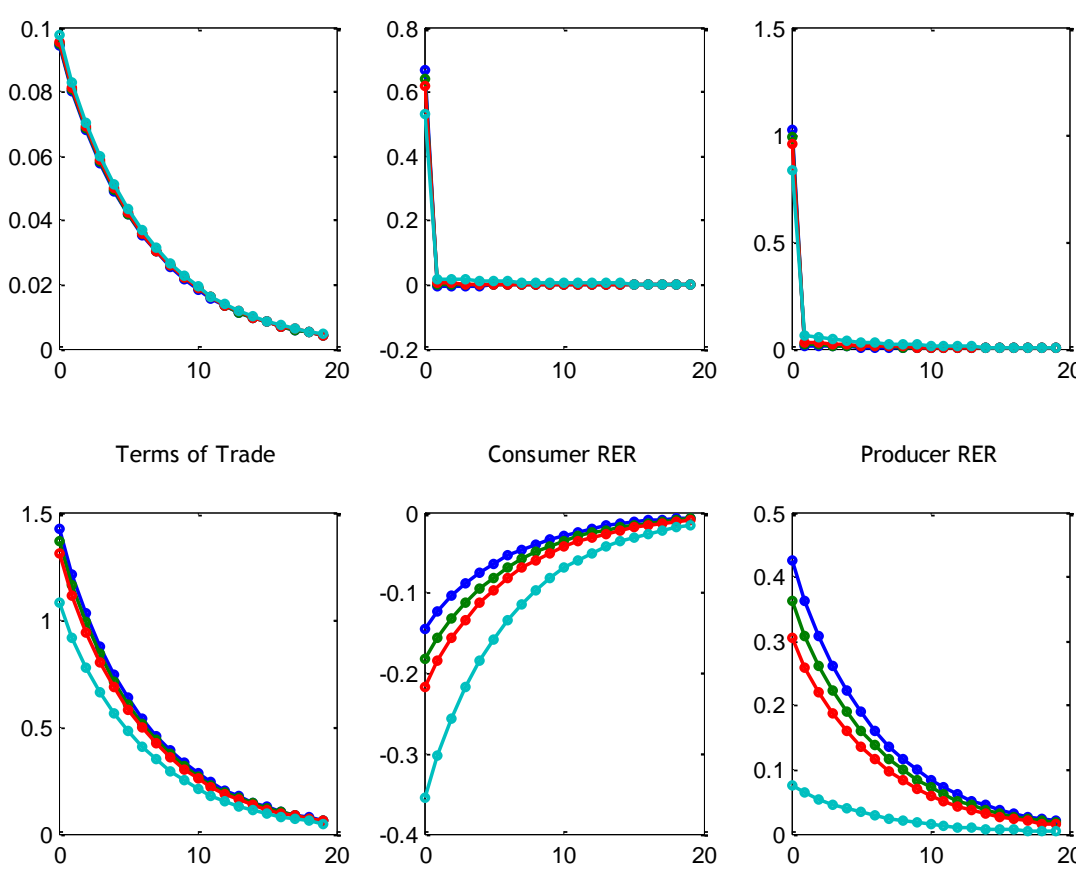

Producer RER
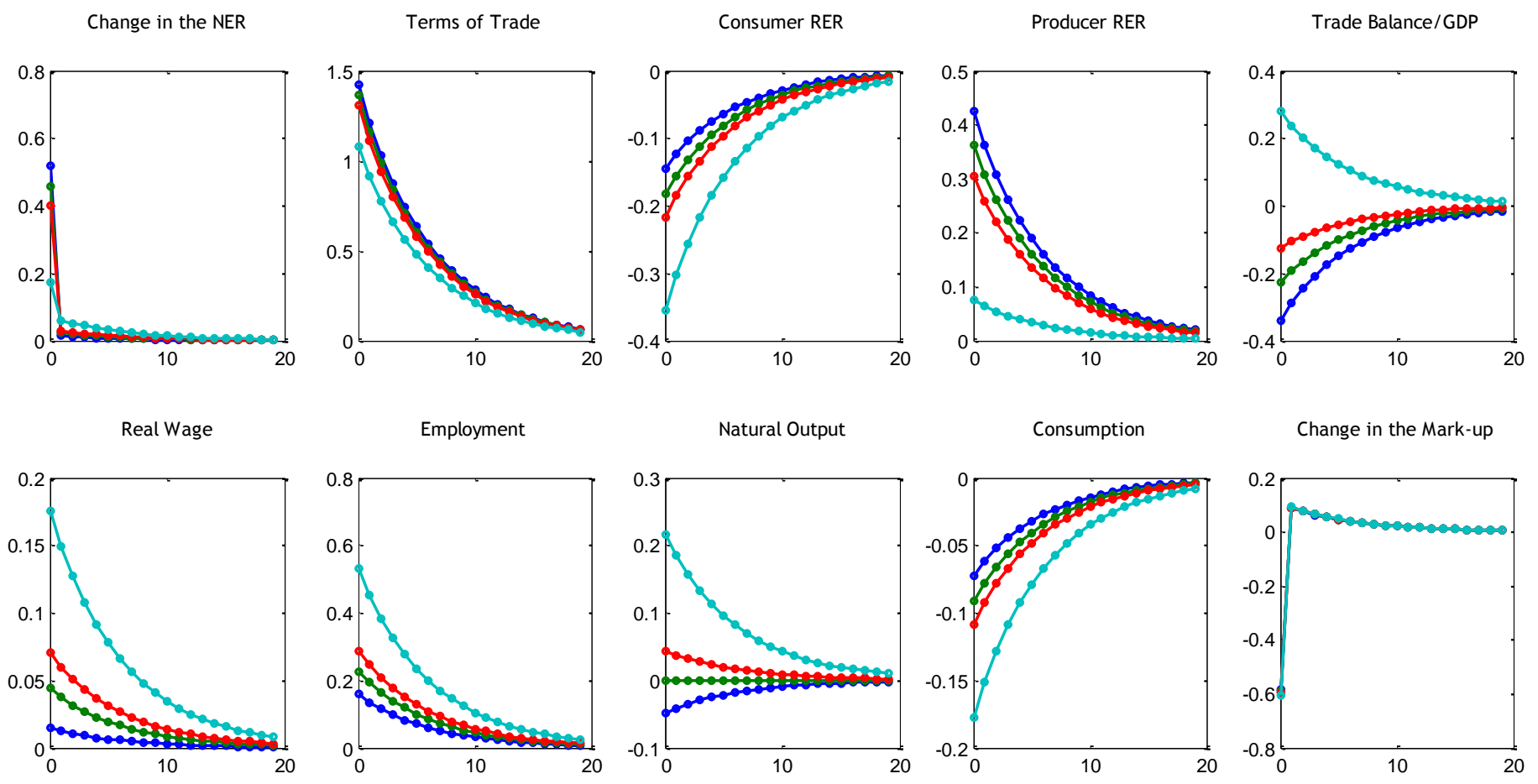